\title{
Modification of Lattice Structures and Mechanical Properties of Metallic Materials by Energetic Ion Irradiation and Subsequent Thermal Treatments
}

\author{
Akihiro Iwase ${ }^{1,2, *}$ and Fuminobu Hori ${ }^{2}$ \\ 1 The Wakasa Wan Energy Research Center, Tsuruga, Fukui 914-0192, Japan \\ 2 Department of Quantum and Radiation Engineering, Osaka Prefecture University, Sakai, Osaka 599-8531, \\ Japan; horif@mtr.osakafu-u.ac.jp \\ * Correspondence: aiwase@werc.or.jp or iwase@mtr.osakafu-u.ac.jp
}

Received: 13 January 2020; Accepted: 10 March 2020; Published: 16 March 2020

\begin{abstract}
When materials are irradiated with high-energy ions, their energies are transferred to electrons and atoms in materials, and the lattice structures of the materials are largely changed to metastable or non-thermal equilibrium states, causing the modification of several physical properties. There are two processes for the material modification by ion irradiation; one is "the irradiation-enhanced process", and the other is "the irradiation-induced process". In this review, two kinds of recent results for the microstructural changes and the modifications of mechanical properties will be summarized: one is the hardness modification of dilute aluminum alloys, which is a result of the irradiation-enhanced process, and the other is the hardness modification of Ni-based intermetallic compounds as a result of the irradiation-induced process. The effect of the subsequent thermal treatment on the microstructures and the hardness for ion-irradiated dilute aluminum alloys is quite different from that for Ni-based intermetallic compounds. This result reflects the difference between the irradiation-enhanced process and the irradiation-induced process. Finally, possibilities of the ion irradiation and subsequent thermal treatment to industrial applications will also be discussed.
\end{abstract}

Keywords: energetic ion irradiation; modification of lattice structure and hardness; thermal treatment; industrial application

\section{Introduction}

During the penetration of high-energy charged particles in materials, they deposit energies in materials through the (screened) Coulomb interaction with the electrons and atoms of materials [1]. These interactions cause the electronic excitations and the displacements of atoms from their regular lattice sites in the materials. It is well known that energetic electron irradiation has been used for the modification of organic materials such as cross-linking and polymerization [2]. For metals and semiconductors, ion-implantation techniques have often been used for their mechanical and electrical properties [3,4]. For the ion-implantation techniques, the material properties are modified mainly by implanting ions, and in a lot of cases, energies deposited by implanting ions or the resulting lattice defects have never been considered as main factors for the materials' modification. The effects of lattice defects induced by energetic ion irradiation on materials' properties have often been studied in the field of materials related to nuclear power plants [5]. Energetic ion irradiation as well as electron irradiation has also been used as a tool for the simulation of space radiation effects on space equipment [6]. However, such studies for nuclear power plants and space developments have treated the negative effects of ion irradiation (so-called "radiation damage") on materials' properties. 
In our recent studies, we have positively used the energies deposited by energetic ion/electron irradiation for the modification of materials properties such as the mechanical properties [7-23], magnetic properties [24-37], and optical properties [38] of metallic and oxide materials.

For the materials' modification by ion irradiation, two kinds of processes can be used; an "irradiation-induced process" and "irradiation-enhanced process". Through the radiation-induced process, the states of materials tend to be changed from the thermal equilibrium states to the thermally non-equilibrium or the metastable states. Through the radiation-enhanced process, the states of materials, which are already non-equilibrium or metastable before the irradiation, tend to become close to the thermally equilibrium states from the non-equilibrium states. The difference in irradiation effects between these two processes remarkably appears during the subsequent thermal treatment at elevated temperatures after the ion irradiation. By the subsequent thermal treatment, the material states obtained by the irradiation-induced process tend to recover to the original thermal equilibrium states (i.e., the states before the irradiation). While on the other hand, the material states obtained by the radiation-enhanced process tend to become further closer to a thermal equilibrium state by the subsequent thermal treatment. Therefore, by the combination of energetic ion irradiation and the subsequent thermal treatments, we can control the materials' states and obtain the resulting several physical properties, which cannot be realized by conventional material processing.

In the following chapters, we will summarize our recent experimental results about the modification of the hardness by ion irradiations for two kinds of metallic materials; dilute aluminum alloys [7-9,17,19] and nickel-based intermetallic compounds $[11,13,15,16,18,20,21]$. The former is an example of the materials' modification through the irradiation-enhanced process, and the latter is that through the irradiation-induced process. We will also discuss the effects of the thermal treatment at elevated temperatures on their structures and the hardness of the ion-irradiated materials. Finally, we will mention the possibilities of the hardness modification by the energetic ion irradiation for industrial applications.

\section{Modification of the Microstructures and the Surface Hardness of Dilute Aluminum Alloys}

Although a pure aluminum metal has a light mass and possesses an excellence in corrosion-resistance, as well as electrical and thermal conductivities, a disadvantage of this metal is its low mechanical strength. A well-known method for its strengthening is the age-treatment of supersaturated alloys. To obtain a sufficient strength by this method, the supersaturated alloys need to be kept at elevated temperatures for long periods of time. In our study, we have tried to increase the surface hardness of several dilute aluminum alloys by the energetic ion irradiation at room temperature for shorter periods of time. The subsequent thermal treatments after the ion irradiation have also been performed in order to obtain the higher hardness of the alloys. Here, the results of our research performed for the past decade will be summarized.

\subsection{Experimental Procedure}

Two binary alloys, $\mathrm{Al}-2 \mathrm{wt} \% \mathrm{Cu}$ and $\mathrm{Al}-4 \mathrm{wt} \% \mathrm{Cu}$, and two typical kinds of practical aluminum alloys, $\mathrm{Al}-\mathrm{Cu}-\mathrm{Mg}$ and $\mathrm{Al}-\mathrm{Mg}-\mathrm{Si}$, were chosen for our experiment. The chemical compositions for the two practical aluminum alloys are listed in Table 1.

Table 1. Chemical compositions of Al-Cu-Mg and Al-Mg-Si alloys.

\begin{tabular}{ccccccccc}
\hline & $\mathbf{C u}$ & $\mathbf{M g}$ & $\mathbf{M n}$ & $\mathbf{S i}$ & $\mathbf{F e}$ & $\mathbf{Z n}$ & $\mathbf{C r}$ & Al \\
\hline Al-Cu-Mg & $3.5-4.5$ & $0.4-0.8$ & $0.4-1.0$ & $0.2-0.8$ & 0.7 & 0.25 & 0.1 & balance \\
\hline Al-Mg-Si & 0.1 & $0.35-0.8$ & 0.03 & $0.3-0.7$ & 0.5 & 0.1 & 0.03 & balance \\
\hline
\end{tabular}


They were solution-annealed at $803-823 \mathrm{~K}$ in air and then quenched into iced water. For the unirradiated binary alloys and pure aluminum, to confirm the effect of solution annealing and quenching, the electrical resistivity was measured.

The specimens were irradiated with several energetic ions by using a tandem accelerator at the Takasaki Advanced Radiation Research Institute of National Institutes for Quantum and Radiological Science and Technology (QST-Takasaki). The ion species and energies used in the present experiment are listed in Table 2.

Table 2. Ion species and energies.

\begin{tabular}{ccccc}
\hline Alloys & \multicolumn{3}{c}{ Ion Species and Energies } \\
\hline $\begin{array}{c}\mathrm{Al}-2 \mathrm{wt} \% \mathrm{Cu} \\
\mathrm{Al}-4 \mathrm{wt} \% \mathrm{Cu}\end{array}$ & $4.5 \mathrm{MeV} \mathrm{Al}$ & $4.5 \mathrm{MeV} \mathrm{Ni}$ & $16 \mathrm{MeV} \mathrm{Au}$ \\
\hline $\mathrm{Al}-\mathrm{Cu}-\mathrm{Mg}$ & $5 \mathrm{MeV} \mathrm{Al}$ & & $10 \mathrm{MeV} \mathrm{I}$ & $16 \mathrm{MeV} \mathrm{Au}$ \\
\hline $\mathrm{Al}-\mathrm{Mg}-\mathrm{Si}$ & $5.4 \mathrm{MeV} \mathrm{Al}$ & $7.3 \mathrm{MeV} \mathrm{Fe}$ & $10 \mathrm{MeV} \mathrm{I}$ & $16 \mathrm{MeV} \mathrm{Au}$ \\
\hline
\end{tabular}

All the irradiations were carried out at room temperature. After the irradiation, the micro Vickers hardness with the load of $10 \mathrm{gf}$ was measured as a function of ion fluence. As the indent depth of micro Vickers measurement is about $2 \mu \mathrm{m}$ even for the load of $10 \mathrm{gf}$, the micro Vickers test measures the hardness not only for the irradiated region but also for the region not affected by the irradiation. To examine more exactly the change in hardness near the specimen surface, a nanoindentation test was also performed for the two kinds of the practical aluminum alloys at the National Institute for Materials Science (NIMS). For comparison, we also measured the micro Vickers hardness for the specimens thermally aged at elevated temperatures. The microstructures were analyzed by using an atom probe tomography (APT) at the Central Research Institute of Electric Power Industry (CRIEPI) for solution-annealed and quenched specimens, ion-irradiated specimens, and thermally aged specimens. The effect of the thermal aging, which was performed after the irradiation, was also investigated. The details of the experimental procedure are described in our previous reports $[7-9,17,19]$.

\subsection{Results and Discussion}

2.2.1. Effects of Ion Irradiation on the Microstructure and Surface Hardness of the Dilute Aluminum Alloys

First of all, the results for the binary alloys are discussed [19]. Figure 1 shows the $\mathrm{Cu}$ content dependence of the electrical resistivity for the pure $\mathrm{Al}$ and the $\mathrm{Al}-2 \% \mathrm{Cu}$ and $\mathrm{Al}-4 \% \mathrm{Cu}$ binary alloy specimens before the irradiation. As can be seen in the figure, the electrical resistivity increases linearly against $\mathrm{Cu}$ content. This result confirms that a homogeneous distribution of isolated $\mathrm{Cu}$ atoms in Al matrix is surely realized by quenching the solution-annealed specimens into iced water. Such a "supersaturated" state is not a thermal equilibrium state but a metastable state far from the thermal equilibrium state.

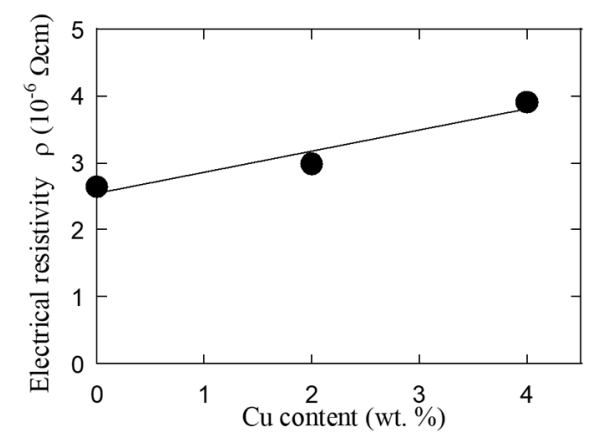

Figure 1. Electrical resistivity as a function of $\mathrm{Cu}$ content for unirradiated pure $\mathrm{Al}$ and $\mathrm{Al}-\mathrm{Cu}$ alloys. 
Figure 2 shows the Vickers hardness as a function of $16 \mathrm{MeV}$ Au ion fluence for $\mathrm{Al}-2 \% \mathrm{Cu}, \mathrm{Al}-4 \% \mathrm{Cu}$, and pure $\mathrm{Al}$ specimens. The hardness for unirradiated specimens strongly depends on the $\mathrm{Cu}$ content. With increasing the $\mathrm{Cu}$ content, the hardness increases. This phenomenon is called "solid solution hardening"; $\mathrm{Cu}$ atoms act as obstacles against dislocation motions, causing the increase in hardness. The figure also shows that the hardness of the two binary alloys largely increases by the irradiation, while for pure $\mathrm{Al}$, the hardness scarcely increases even at higher ion fluence. In addition, the increase in hardness for $\mathrm{Al}-4 \mathrm{wt} \% \mathrm{Cu}$ is larger than that for $\mathrm{Al}-2 \mathrm{wt} \% \mathrm{Cu}$.

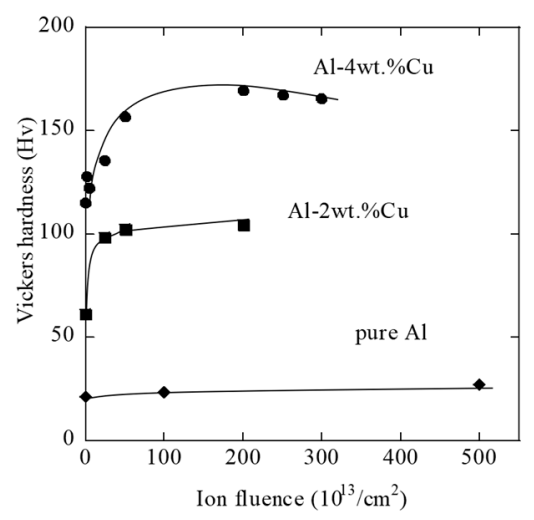

Figure 2. Vickers hardness as a function of $16 \mathrm{MeV} \mathrm{Au}$ ion fluence for pure $\mathrm{Al}, \mathrm{Al}-2 \mathrm{wt} \% \mathrm{Cu}$ alloy and Al-4wt \%Cu alloy.

Figure 3 shows the ion-fluence dependence of Vickers hardness for three kinds of ions. With increasing the ion fluence, the hardness increases and tends to be saturated at higher ion fluence. The change in hardness depends on the irradiating ion species. With increasing the ion mass, the change in hardness becomes larger even at the same fluence.
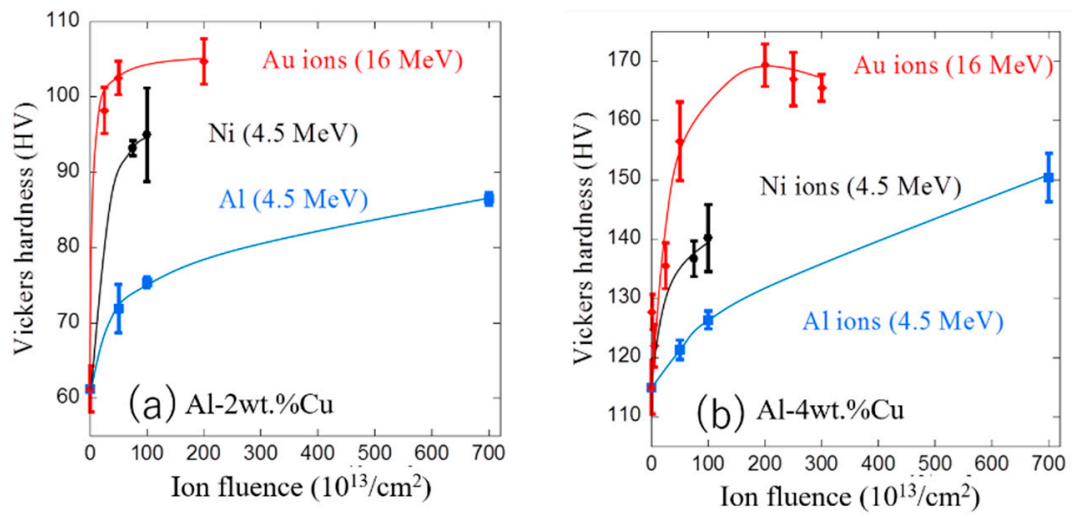

Figure 3. Ion fluence dependence of Vickers hardness of (a) Al-2wt \%Cu alloy and (b) Al-4wt \%Cu alloy for three kinds of ion irradiations.

When energetic ions penetrate a solid, their energy is deposited into the solid mainly through two processes; through the excitation of electrons and through the elastic collisions with atoms. Figure 4 shows the hardness change as a function of the density of ion energy deposited through the elastic collisions, which has been calculated by the SRIM 2008 code [39]. As can be seen in the figure, the change in hardness is well correlated with the density of energy deposited through the elastic collisions, suggesting that the lattice defects produced by the elastic collisions between the irradiating ions and atoms in the target mostly contribute to the hardness increment. This is a reasonable result, because it is well known that in metallic systems, permanent displacements of lattice atoms hardly occur by the energy deposition through the electronic excitation except in the case of swift heavy ion irradiation with very high electronic stopping powers $[40,41]$. 


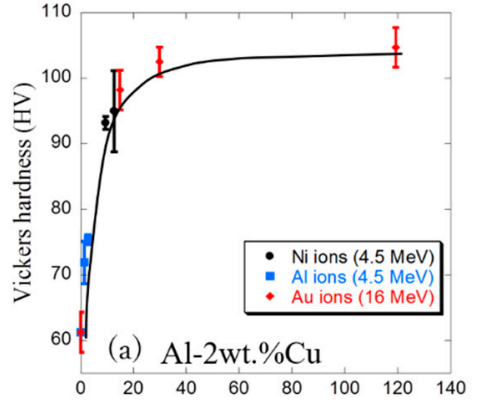

Deposited energy density by elastic collisions $\left(10^{23} \mathrm{eV} / \mathrm{g}\right)$

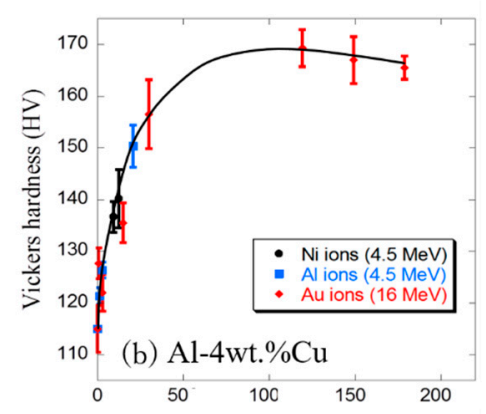

Deposited energy density by elastic collisions $\left(10^{23} \mathrm{eV} / \mathrm{g}\right)$

Figure 4. Elastically deposited energy density dependence of Vickers hardness of (a) Al-2wt \%Cu alloy and (b) Al-4wt \%Cu alloy for three kinds of ion irradiations.

It is particularly worth noting here that the increase in hardness for the irradiation with $\mathrm{Al}$, which is the same as the matrix element of the binary alloys, shows the same dependence on the elastically deposited energy as that for the other ion irradiations. This result eliminates the possibility that the increase in hardness is explained as due to the chemical effect of irradiating ions in target materials. Figures 2-4 clearly imply that not only lattice defects produced by the elastic collisions but also the existence of $\mathrm{Cu}$ atoms in the Al matrix play an important role in the increase in hardness. As discussed later, the increase in hardness for the ion-irradiated dilute aluminum alloys is attributed to the clustering of additive elements such as $\mathrm{Cu}$ atoms.

Figure 5 shows the increase in hardness for the Al-Cu binary alloys irradiated with $16 \mathrm{MeV} \mathrm{Au}$ ions at room temperature and that for the $\mathrm{Al}-\mathrm{Cu}$ alloys thermally aged at $453 \mathrm{~K}$ as a function of processing time. Here, the processing time means the irradiation time or the aging time for the ion-irradiated specimens or the thermally aged specimens, respectively.
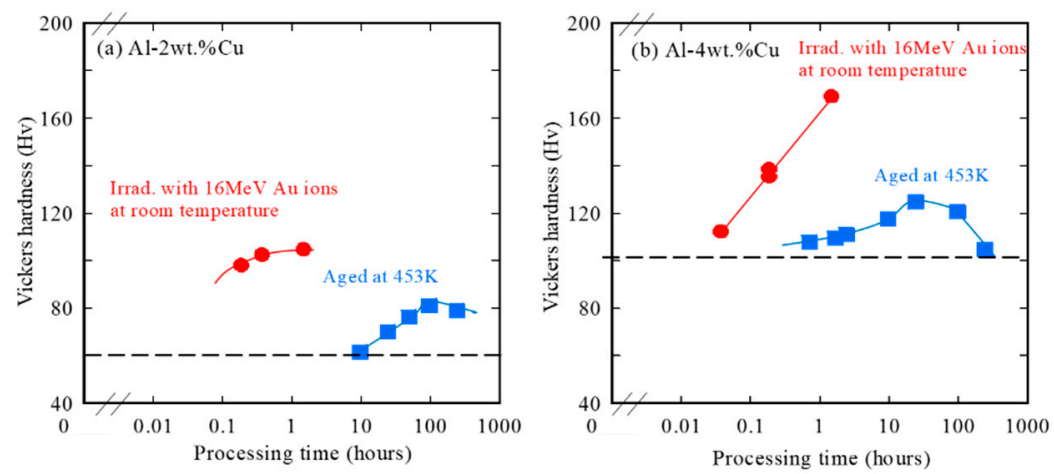

Figure 5. Vickers hardness of (a) Al-2wt \%Cu alloy and (b) Al-4wt \%Cu alloy as a function of processing time. Solid circles for specimens irradiated with $16 \mathrm{MeV}$ Au ions and solid squares for those thermally aged at $453 \mathrm{~K}$. Dashed lines show the hardness values before irradiation or thermal aging.

The figure clearly shows that the hardness of the Al-Cu binary alloys increases much faster by the $\mathrm{Au}$ ion irradiation at room temperature than by the thermal aging at $453 \mathrm{~K}$. Moreover, the maximum hardness values are much larger by the $\mathrm{Au}$ ion irradiation ( $\mathrm{Hv}=100$ and $170 \mathrm{for} \mathrm{Al}-2 \mathrm{wt} \% \mathrm{Cu}$ and $\mathrm{Al}-4 \mathrm{wt} \% \mathrm{Cu}$, respectively) than those by the thermal aging ( $\mathrm{Hv}=80$ and 125 for $\mathrm{Al}-2 \mathrm{wt} \% \mathrm{Cu}$ and $\mathrm{Al}-4 \mathrm{wt} \% \mathrm{Cu}$, respectively).

Next, to consider the industrial applications of the energetic ion irradiation to the hardness modification of dilute aluminum alloys, we discuss the experimental results for two practical aluminum alloys, Al-Cu-Mg alloy $[7,8]$ and Al-Mg-Si alloy $[9,17]$. The former is a practical aluminum alloy that is best known as "Duralumin", and the latter has been used as electrical wire material because of its 
good electrical conductivity. As can be seen in Table 1, the main difference between these two practical $\mathrm{Al}$ alloys is the $\mathrm{Cu}$ concentration. In $\mathrm{Al}-\mathrm{Cu}-\mathrm{Mg}$ alloy, $\mathrm{Cu}$ is a main additive element, while in $\mathrm{Al}-\mathrm{Mg}-\mathrm{Si}$ alloy, the concentration of $\mathrm{Cu}$ is much smaller than in $\mathrm{Al}-\mathrm{Cu}-\mathrm{Mg}$ alloy.

Figures 6 and 7 show the change in Vickers hardness of Al-Cu-Mg and Al-Mg-Si specimens as a function of ion fluence for various ions and as a function of energy deposited through elastic collisions, respectively. The values of the hardness before the irradiation is $120 \mathrm{for} \mathrm{Al}-\mathrm{Cu}-\mathrm{Mg}$ alloy and $67 \mathrm{for}$ $\mathrm{Al}-\mathrm{Mg}$-Si alloy. As in the case of Al-Cu binary alloys, the change in hardness is well correlated with the density of energy deposited through the elastic collisions.
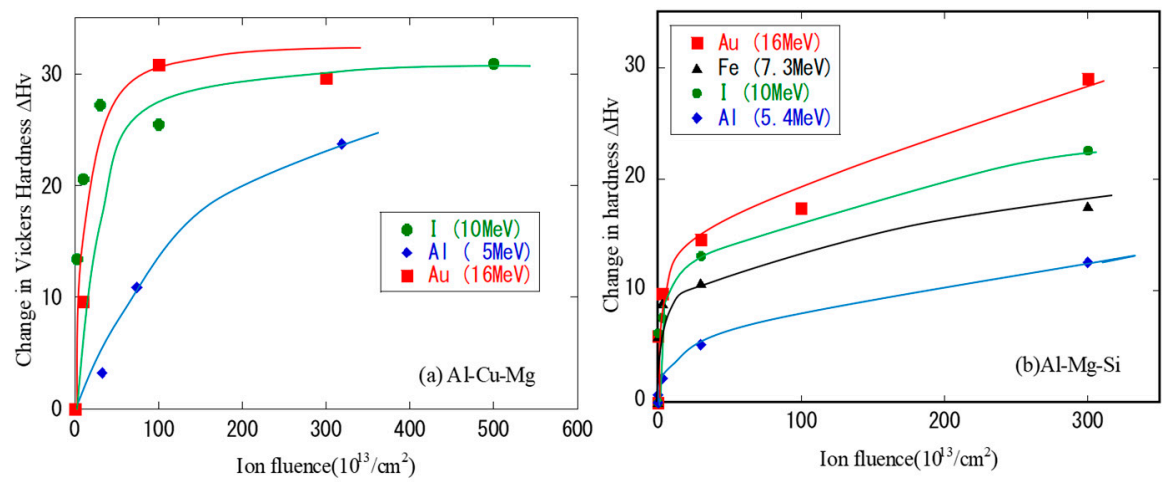

Figure 6. Change in Vickers hardness as a function of ion fluence for (a) $\mathrm{Al}-\mathrm{Cu}-\mathrm{Mg}$ alloy and (b) $\mathrm{Al}-\mathrm{Mg}-\mathrm{Si}$ alloy. The values of hardness before the irradiation is 120 for Al-Cu-Mg alloy and 67 for Al-Mg-Si alloy.
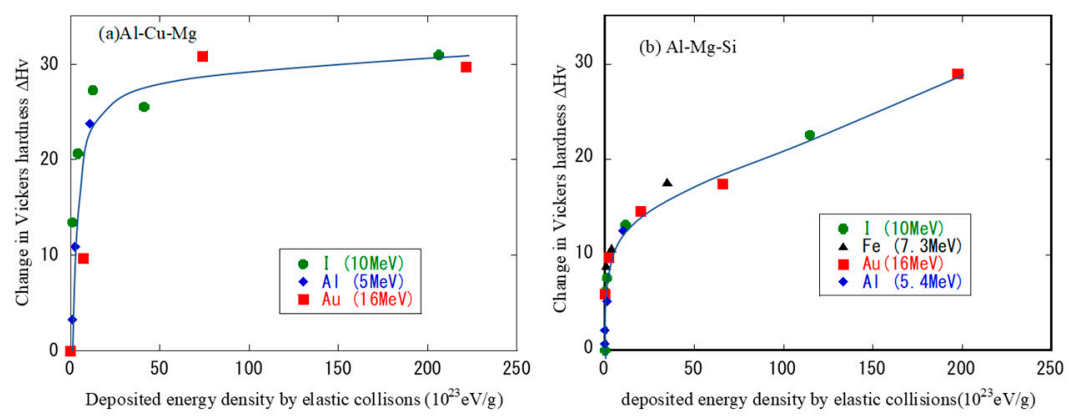

Figure 7. Change in Vickers hardness as a function of deposited energy density by elastic collisions for (a) Al-Cu-Mg alloy and (b) Al-Mg-Si alloy.

Figure 8 shows the result of nanoindentation test for the two practical alloys irradiated with $10 \mathrm{MeV}$ I ions. The figure shows the behavior of hardness for the depth below $150 \mathrm{~nm}$. Even for the same indentation load $(1000 \mu \mathrm{N})$, the indent depth decreases with increasing the ion fluence. Figure 9 indicates the nanoindentation hardness as a function of $10 \mathrm{MeV}$ I ion fluence. The result of the nanoindentation test confirms the increase in hardness near the surface by the ion irradiation. 

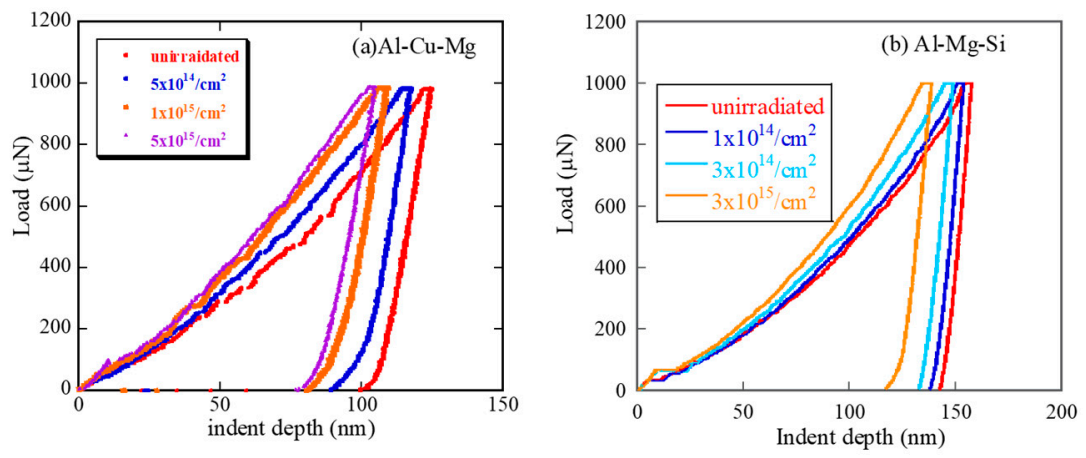

Figure 8. Results of nanoindentation for (a) Al-Cu-Mg alloy and (b) Al-Mg-Si alloy irradiated with $10 \mathrm{MeV}$ I ions.
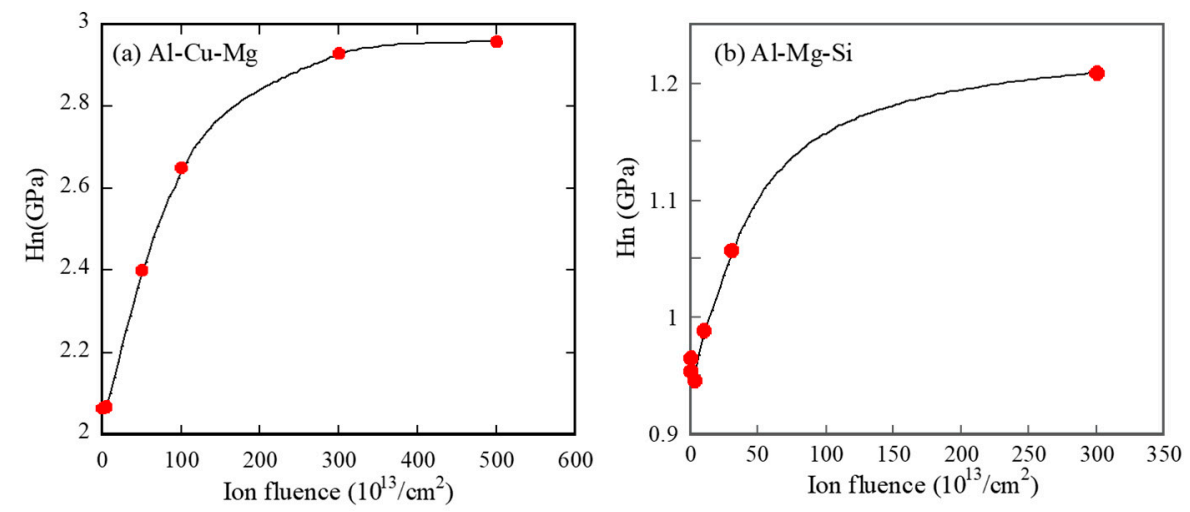

Figure 9. Nanoindentation hardness as a function of $10 \mathrm{MeV}$ I ion fluence for (a) Al-Cu-Mg alloy and (b) Al-Mg-Si alloy.

From the data of nanoindentation measurements, not only the hardness but also the elastic modulus can be deduced by using the slope of the stress-strain curve. As the elastic modulus is a more essential physical property that originates from the atomic force among lattice atoms, the change in elastic modulus by the ion irradiation is quite interesting. However, only by using the present result, it is difficult to discuss clearly the effect of the ion irradiation on the elastic modulus. Therefore, in the present report, we have solely focused on hardness change.

Figure 10a shows the change in Vickers hardness as a function of processing time for the $\mathrm{Al}-\mathrm{Cu}-\mathrm{Mg}$ specimens irradiated with $10 \mathrm{MeV}$ iodine ions at room temperature and for those thermally aged at 423 $\mathrm{K}$ and $453 \mathrm{~K}$. The behavior of hardness change of Al-Cu-Mg alloy is similar to the case of Al-Cu binary alloys; for the specimens irradiated at room temperature, the hardness increases far more rapidly than that for the thermally aged specimens. Only 3.5 hours are required to reach a Vickers hardness of 165, which is about the same as the maximum hardness when the specimen is thermally aged at $423 \mathrm{~K}$ for 100 hours. A more rapid increase in hardness by the ion irradiation than by the thermal aging has been observed also for Al-Mg-Si alloy (see Figure 10b). 

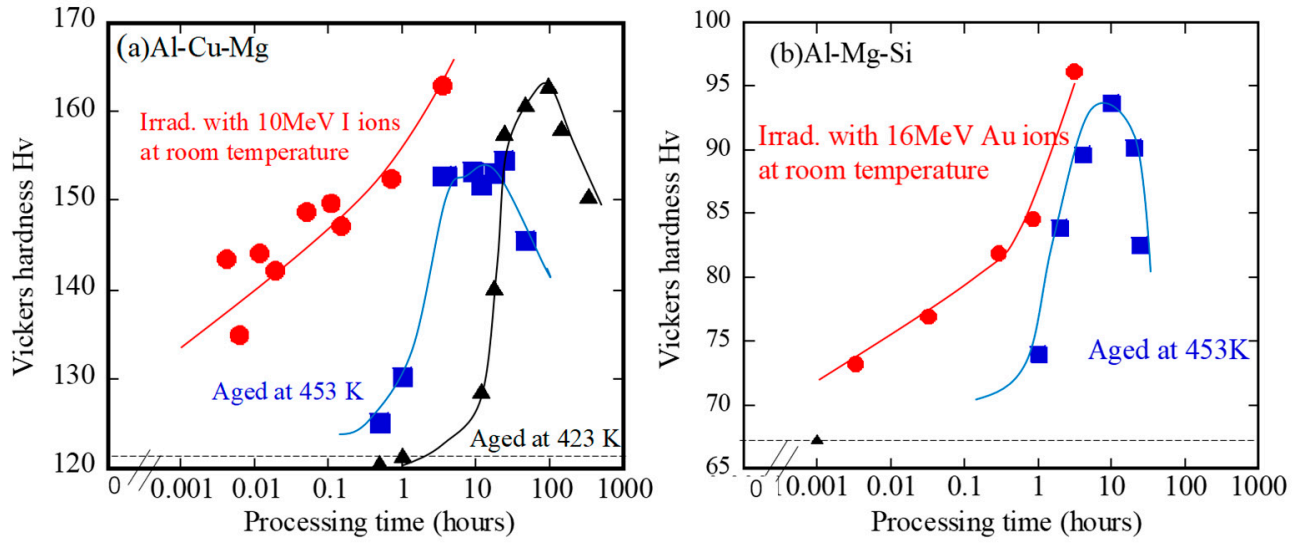

Figure 10. Comparison of the change in Vickers hardness between irradiated specimens and thermally aged specimens as a function of processing time, (a) Al-Cu-Mg alloy and (b) Al-Mg-Si alloy. Dashed lines show the values of hardness before irradiation or thermal aging.

The microstructures of the Al-Cu-Mg specimen irradiated with $10 \mathrm{MeV}$ I ions observed by using the atom probe tomography (APT) are shown in Figure 11.

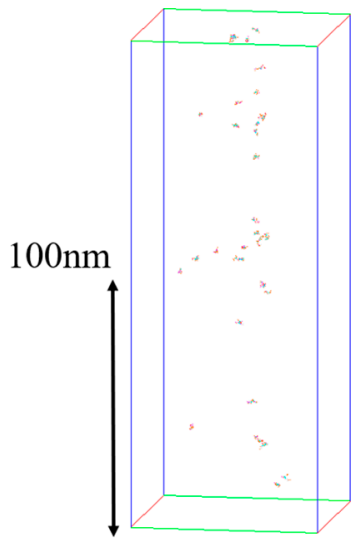

(a)

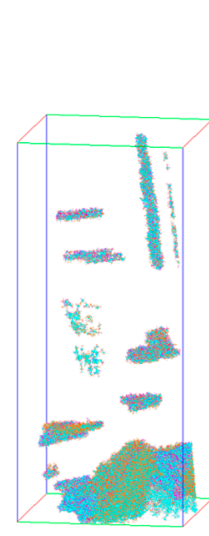

(b)

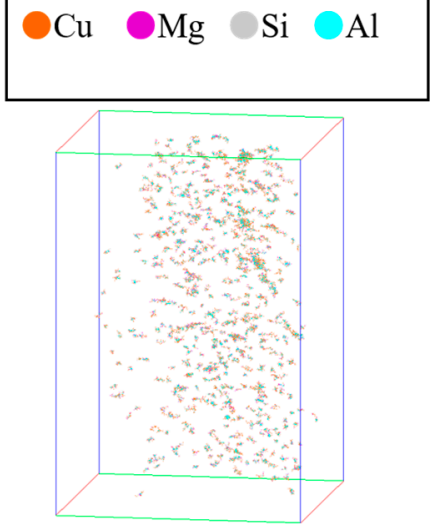

(c)

Figure 11. Atom probe elemental mapping for (a) solution-annealed and quenched specimen, (b) specimen aged at $423 \mathrm{~K}$ for 4 days, and (c) specimen irradiated with iodine ions to the fluence of $1 \times 10^{15} / \mathrm{cm}^{2}$ at room temperature.

The results for unirradiated specimen and those thermally aged at $423 \mathrm{~K}$ for 4 days are also shown in the figure. As precipitates in the unirradiated and the irradiated specimens were hardly observed by a normal atom probe elemental mapping, we used the cluster analysis, and therefore, all the constituent atoms including $\mathrm{Al}$ atoms can be seen in Figure 11. The detail of the cluster analysis has been described in ref. [7,9]. In the thermally aged specimen, we can see some needle-like and plate-like precipitates of several tens of nanometers in size. As the solubility of the additive elements such as $\mathrm{Cu}$ and $\mathrm{Mg}$ in aluminum is very low at room temperature, the additive elements, which are dispersed as isolated atoms in a supersaturated specimen, diffuse over a long distance at elevated temperatures, resulting in coarse precipitates. On the other hand, in the ion-irradiated specimen, as shown in Figure 11c, many small precipitates of about $3 \mathrm{~nm}$ in diameter are homogeneously distributed. This phenomenon can be explained as follows; when the supersaturated aluminum alloy is irradiated with energetic ions, point defects (interstitial atoms and vacancies) are produced by elastic collisions. Such point defects can diffuse rapidly in the alloy even at room temperature. The point defects interact selectively with additive elements such as copper and magnesium, and the diffusion of these 
elements is enhanced by the diffusion of point defects. As a result, a precipitation of the additive elements occurs at temperatures much lower than that for the thermal aging. This phenomenon is caused by an "irradiation-enhanced process", because the supersaturated state, which is produced by quenching the solution-annealed samples to iced water, exists as a non-thermal equilibrium state, and this non-thermal equilibrium state tends to become close to a thermal equilibrium state by the irradiation. However, under the ion irradiation, the precipitation occurs through a short-distance diffusion, and nanometer-sized precipitates are produced. Such small precipitates can act as effective obstacles for dislocation motions, causing a remarkable increase in hardness at room temperature as compared with the case of thermal aging. A similar precipitation of additional elements ( $\mathrm{Mg}$ and $\mathrm{Si})$ by the ion irradiation can be found also in Al-Mg-Si specimens. In the unirradiated specimen, $\mathrm{Mg}$ and $\mathrm{Si}$ atoms are nearly homogeneously distributed. By the ion irradiation, small sized $\mathrm{Mg}$ and $\mathrm{Si}$ precipitates are produced. In the thermally aged specimen, the size of precipitates of $\mathrm{Mg}$ and $\mathrm{Si}$ atoms is much larger than in the ion-irradiated specimen.

The effectiveness of nanometer-sized precipitates for the hardness increase in metallic alloys has also been reported in our previous paper [42], in which nanometer-sized $\mathrm{Cu}$ precipitates produced by the irradiation in Fe-Cu binary alloys provide a large increase in hardness. This phenomenon can be explained by using the Russell-Brown model [43].

2.2.2. Effect of Subsequent Thermal Treatments after the Irradiation on the Microstructures and Hardness of the Dilute Aluminum Alloys

Until now, we have discussed the effect of energetic ion irradiation on the microstructures and the hardness of various dilute aluminum alloys. From now on, the effects of the subsequent thermal aging at elevated temperatures on the hardness of ion-irradiated specimens are discussed.

Figure 12 shows the aging time dependence of Vickers hardness during the thermal aging at $423 \mathrm{~K}$ for the $\mathrm{Al}-\mathrm{Cu}-\mathrm{Mg}$ specimen pre-irradiated with $10 \mathrm{MeV}$ I ions at room temperature. The data for the unirradiated specimen are also plotted.

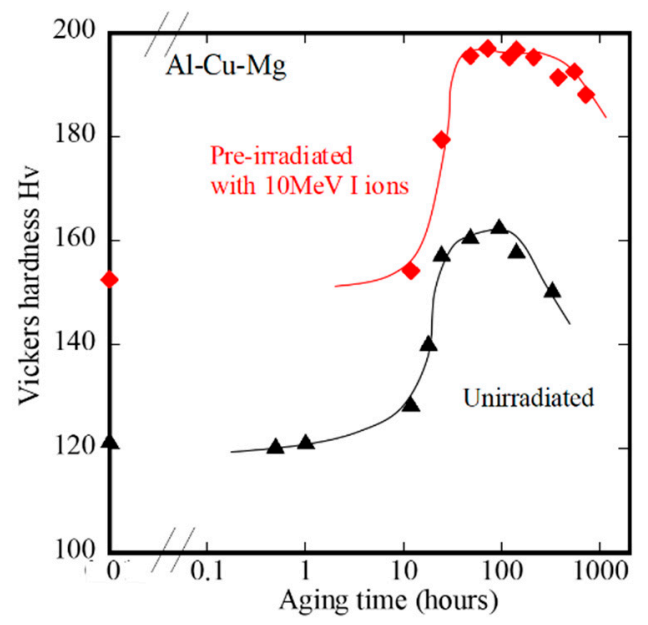

Figure 12. Vickers hardness as a function of aging time for $\mathrm{Al}-\mathrm{Cu}-\mathrm{Mg}$ specimen pre-irradiated with $10 \mathrm{MeV}$ ions to the fluence of $5 \times 10^{15} / \mathrm{cm}^{2}$. Data for unirradiated specimen are also plotted. Aging temperature is $423 \mathrm{~K}$.

The value of the hardness for the irradiated specimen before the thermal aging is larger by 30 than that for the unirradiated specimen. It increases furthermore by the thermal aging. After 50 hours of aging, the hardness reaches the maximum value of nearly 200. The maximum hardness is kept unchanged even after 250 hours of aging, while for unirradiated specimen, the hardness reaches only 160 and then decreases after 100 hours of aging (so-called over-aging). The effect of the subsequent thermal aging on the microstructure can be seen in Figure 13 as a result of APT observation. 
As Figure 13a,b show the normal atom probe elemental maps, they indicate the distribution of $\mathrm{Cu}, \mathrm{Mg}$, and $\mathrm{Si}$ atoms, but that of $\mathrm{Al}$ atoms is not shown in the figures. Figure 13a shows the effect of thermal aging at $423 \mathrm{~K}$ for 30 days on the unirradiated specimen. Precipitates with a scale of several tens nanometer appear. A long-time aging causes the coarsening of precipitates, resulting in the decrease in hardness. The effect of pre-irradiation at room temperature and the subsequent thermal aging on the microstructure of precipitates is quite different from that of only the thermal aging. The size of precipitates in Figure 13b is smaller on average than that in Figure 13a, but the number density of precipitates in Figure 13b is larger than that of Figure 13a.

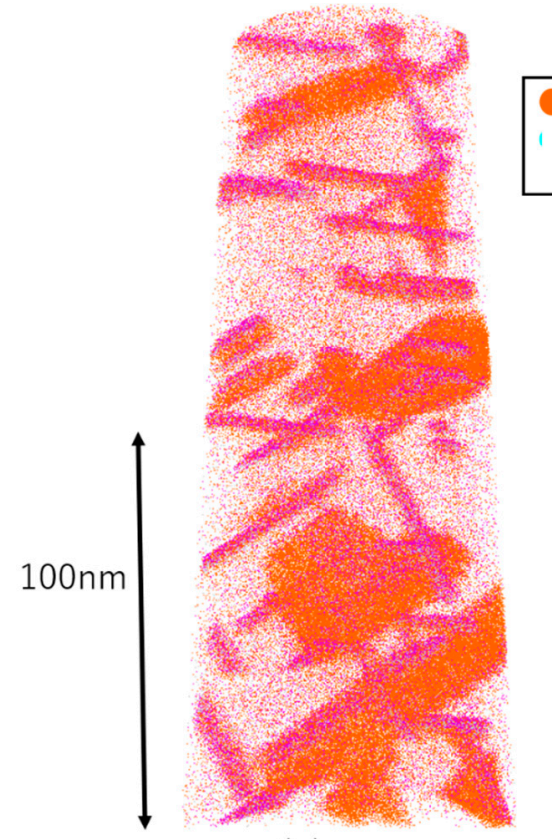

(a)
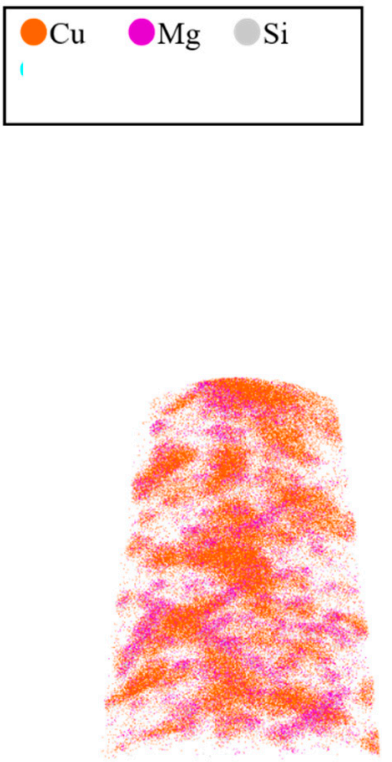

(b)

Figure 13. Atom probe elemental mapping for (a) specimen unirradiated but only aged at $423 \mathrm{~K}$ for 30 days, and (b) specimen pre-irradiated with iodine ions to the fluence of $5 \times 10^{15} / \mathrm{cm}^{2}$ and subsequently aged at $423 \mathrm{~K}$ for 30 days.

The effect of the subsequent thermal aging on the microstructure of precipitates and hardness can be explained as follows; first of all, nanometer-sized precipitates are produced by the ion irradiation. Then, during the subsequent thermal aging, isolated solute atoms diffuse preferentially to already existing small precipitates, and the growth of precipitates occurs. The experimental result implies that the size and the number of precipitates grown by the subsequent thermal aging (Figure 13b) is more effective for the hardness increase than those produced only by the irradiation (Figure 11c).

The change in the microstructure of precipitates produced by the irradiation and/or the thermal aging is summarized schematically in Figure 14 in terms of the free energy. The abscissa of the figure means the coordinates of lattice atoms in the specimens, which corresponds to the microstructure of the specimens. 


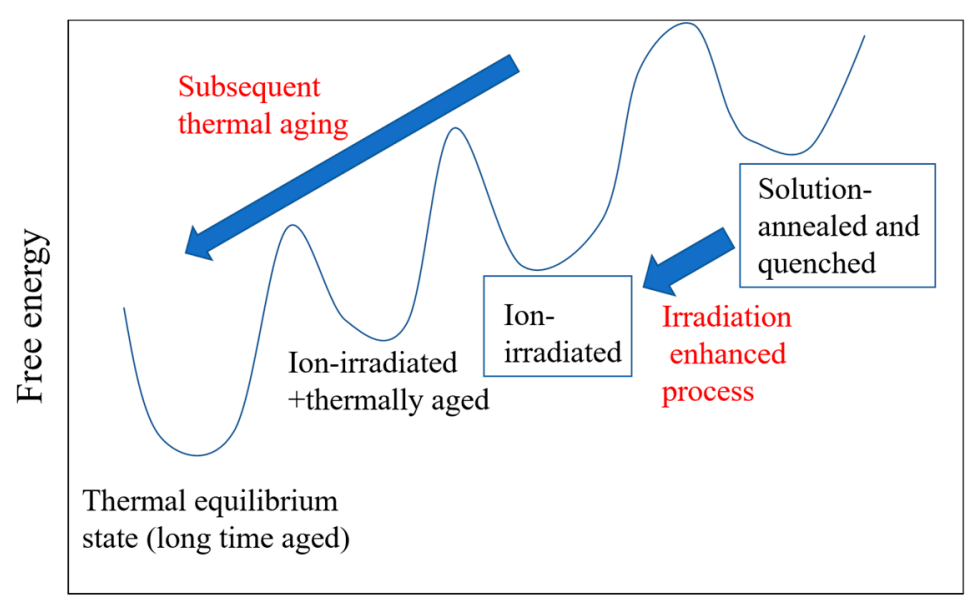

Coordinates of lattice atoms

Figure 14. Schematic diagram of change in free energy for "irradiation-enhanced process" and subsequent thermal aging.

The microstructure of the precipitates that appears after 30-day thermal aging is considered to be nearly the thermal equilibrium state, whereas the free energy of the supersaturated specimen is higher than that of the thermal equilibrium structure. The ion irradiation and the subsequent thermal aging reduce the free energy of the specimen, and the microstructure of the specimen tends to recover to the thermal equilibrium state. However, it is not a complete thermal equilibrium state but a metastable state, the free energies of which are still higher than that for the thermal equilibrium state. A similar effect of the subsequent thermal aging on the hardness has been observed for Al-Mg-Si specimens (see Figure 15).

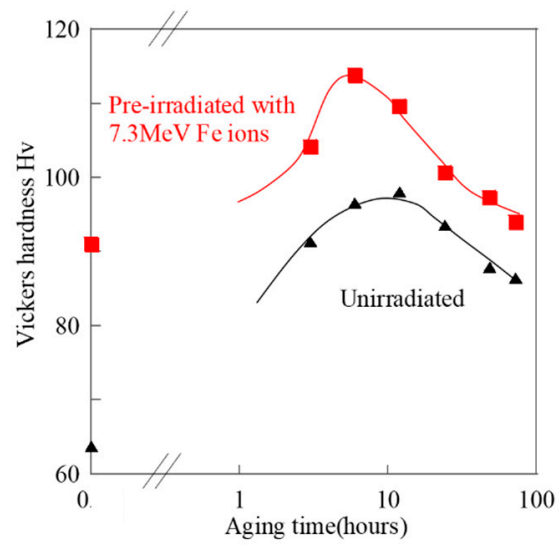

Figure 15. Vickers hardness as a function of aging time for specimen pre-irradiated with 7.3 MeV Fe ions to the fluence of $5.65 \times 10^{15} / \mathrm{cm}^{2}$. Data for unirradiated specimen are also shown. Aging temperature is $453 \mathrm{~K}$.

In the present paper, we have never considered the indenter size effect (ISE), which mainly appears in the hardness at the shallow depth of the specimens. To analyze the hardness data more quantitatively, we will consider the ISE in our future study.

\section{Modification of Lattice Structures and Surface Hardness of Ni-Based Intermetallic Compounds}

Intermetallic compounds have the ordered structures. They are more sensitive against the energetic ion irradiation than pure metals or dilute alloys, because not only atomic displacements but also position exchanges of atoms of different types affect their atomic arrangements and physical properties. For the past decade, we have studied the effects of energetic ion irradiation on the lattice 
structures and the hardness of several Ni-based intermetallic compounds $\left(\mathrm{Ni}_{3} \mathrm{~V}\right.$ [11,13], $\mathrm{Ni}_{3} \mathrm{Al}$ [16], $\mathrm{Ni}_{3} \mathrm{Nb}[18,20,21]$, and $\left.\mathrm{Ni}_{3} \mathrm{Ta}[18,20,21]\right)$. As the specimens were sufficiently homogenized at elevated temperatures for a long time, the lattice structures of the specimens before the irradiation are consistent with the structures that are present in the thermal equilibrium phase diagrams at room temperature and atmosphere pressure. Therefore, the modifications of lattice structures and physical properties of the intermetallic compounds by energetic ion irradiation were obtained through "irradiation-induced process". In our previous papers, the effects of $\mathrm{He}, \mathrm{Al}, \mathrm{Ni}, \mathrm{I}, \mathrm{Au}$, and Xe ion irradiations with the energies of 1-200 MeV have been discussed in terms of ion species, energy, and fluence dependence. In the present report, for the sake of clarity, only the result for $16 \mathrm{MeV} \mathrm{Au}$ ion irradiation and the subsequent thermal treatment will be discussed.

\subsection{Experimental Procedure}

$\mathrm{Ni}_{3} \mathrm{~V}, \mathrm{Ni}_{3} \mathrm{Al}, \mathrm{Ni}_{3} \mathrm{Nb}$, and $\mathrm{Ni}_{3} \mathrm{Ta}$ intermetallic compounds were made by arc melting and thermally annealed at elevated temperatures for a long time. They were irradiated with $16 \mathrm{MeV}$ Au ions at room temperature by using a tandem accelerator at QST-Takasaki. The changes in lattice structure by the ion irradiation were investigated at room temperature by a grazing incidence $X$-ray diffraction (GIXD) method. As the incident angle of X-ray $(\mathrm{Cu} \mathrm{K} \alpha)$ was kept at 0.5 degrees, the GIXD only observed the lattice structure of specimens from the surface to the depth of about $200 \mathrm{~nm}$. As the range of $16 \mathrm{MeV} \mathrm{Au}$ ion was about $1.5 \mu \mathrm{m}$, the GIXD surely observed the region where the ion energy was deposited. For $\mathrm{Ni}_{3} \mathrm{~V}$ thin specimens, to observe the lattice microstructures, the transmission electron microscope (TEM) was also used. For $\mathrm{Ni}_{3} \mathrm{Nb}$ and $\mathrm{Ni}_{3} \mathrm{Ta}$ specimens, to investigate the irradiation effect on atomic arrangements around $\mathrm{Nb}$ or Ta atoms, the EXAFS (extended X-ray Absorption Fine Structure) measurements were performed at the Photon Factory of High Energy Accelerator Research Organization (KEK-PF). To estimate the surface hardness, the Vickers microhardness test with a load of $10 \mathrm{gf}$ was conducted. The effect of the thermal treatments, which were performed after the irradiation, on the lattice structure and the hardness was also investigated. The details of the experimental procedure have been described in our previous reports $[13,20]$.

\subsection{Results and Discussion}

3.2.1. Effects of $16 \mathrm{MeV} \mathrm{Au}$ Ion Irradiation on the Lattice Structure and Surface Hardness of the Ni-Based Intermetallic Compounds

Figure 16 shows the phase diagram for Ni-V binary alloy and the schematic diagram of the $\mathrm{D}_{22}$ and $\mathrm{A} 1$ lattice structures. The stoichiometric $\mathrm{Ni}_{3} \mathrm{~V}$ alloy has a tetragonal structure $\left(\mathrm{DO}_{22}\right.$ structure) at room temperature, and above $1300 \mathrm{~K}$, the $\mathrm{D}_{22}$ lattice structure transforms into the disordered fcc (face centered cubic) structure (A1 structure). 


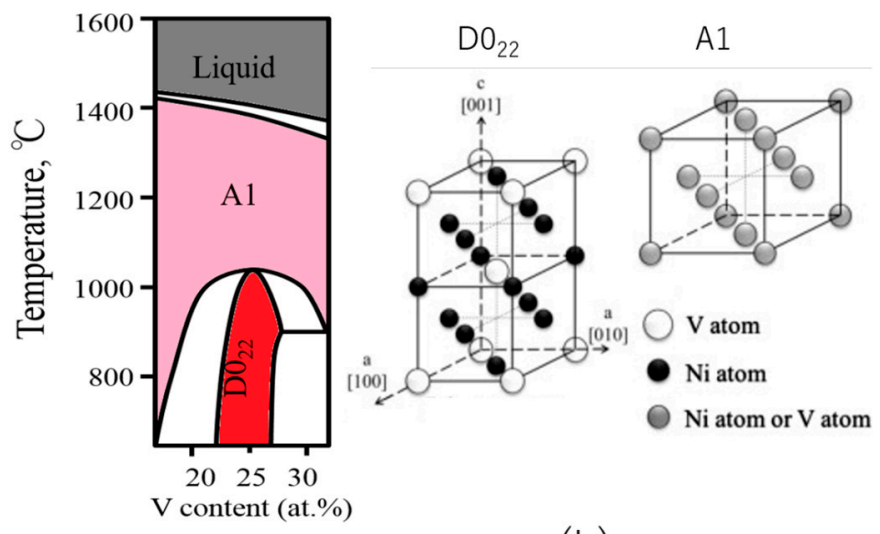

(a)

(b)

Figure 16. (a) Phase diagram of Ni-V binary alloy near the V concentration of $25 \%$ and (b) crystal structures of $\mathrm{DO}_{22}$ (tetragonal) and $\mathrm{A} 1$ (fcc).

Figure 17 shows the GIXD spectra for the unirradiated and $16 \mathrm{MeV} \mathrm{Au}$ ion-irradiated $\mathrm{Ni}_{3} \mathrm{~V}$ specimens. In the spectrum for the unirradiated specimen, two peaks corresponding to the $\mathrm{D}_{22}$ structure are clearly observed. For the specimen irradiated to the fluence of $5 \times 10^{14} / \mathrm{cm}^{2}$, the two peaks merge, and the (200) peak for the A1 structure appears.

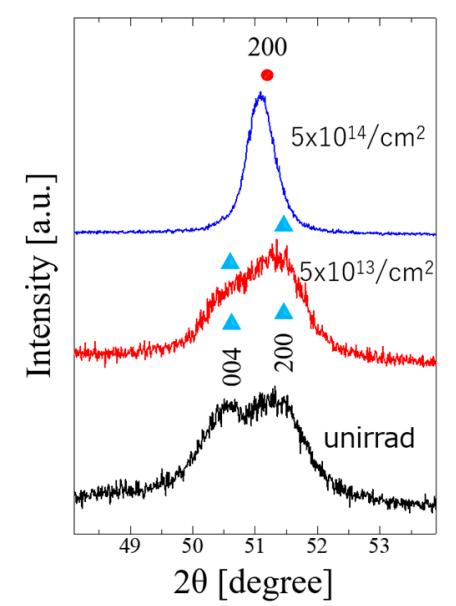

Figure 17. Grazing incidence X-ray diffraction (GIXD) spectra for $16 \mathrm{MeV}$ Au-irradiated $\mathrm{Ni}_{3} \mathrm{~V}$. Solid triangle for $\mathrm{D}_{22}$ peaks and solid circle for $\mathrm{A} 1$ peak.

In Figure 18, the selected area diffraction spots and the TEM bright field images are shown. The superlattice spots in the diffraction pattern and the lamellar-like microstructure, which are features of the $\mathrm{D}_{22}$ (tetragonal) structure, completely disappear after $\mathrm{Au}$ ion irradiation, and only the fundamental spots for the fcc (A1) phase are recognized in the diffraction pattern. 


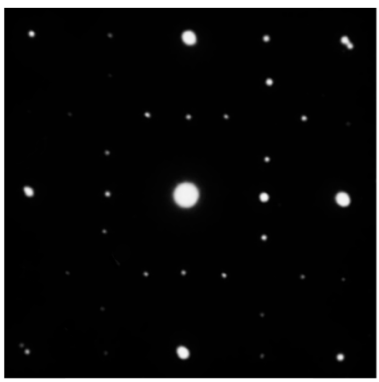

(a) unirrrad

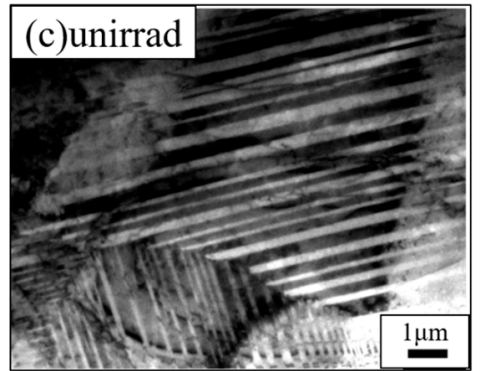

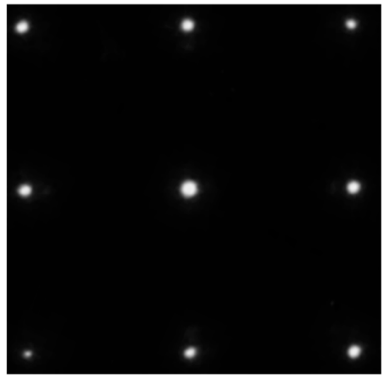

(b) $5 \times 10^{14} \mathrm{~cm}^{-2}$

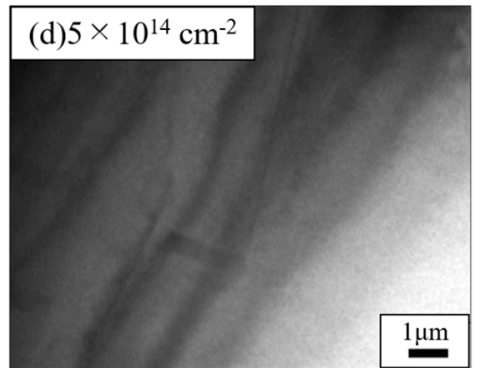

Figure 18. Selected area electron diffraction patterns for (a) unirradiated $\mathrm{Ni}_{3} \mathrm{~V}$ and (b) $16 \mathrm{MeV}$ $\mathrm{Au}$ ion-irradiated $\mathrm{Ni}_{3} \mathrm{~V}$. TEM bright field images (c) for unirradiated $\mathrm{Ni}_{3} \mathrm{~V}$ and (d) for $16 \mathrm{MeV} \mathrm{Au}$ ion-irradiated $\mathrm{Ni}_{3} \mathrm{~V}$.

The experimental results definitely indicate that by the ion irradiation, the lattice structure of $\mathrm{Ni}_{3} \mathrm{~V}$ is transformed from the thermal equilibrium structure at room temperature $\left(\mathrm{D}_{22}\right.$ structure) to the fcc (A1) structure, which is the thermal equilibrium structure at quite high temperatures (above $1300 \mathrm{~K}$ ). There are two possible explanations for the phase transformation of $\mathrm{Ni}_{3} \mathrm{~V}$ by the ion irradiation. One is based on the elastic thermal spike model; as the cascade of collisions initiated by the irradiating ions deposits high-density energy in a narrow region, and the temperature of this region instantaneously increases. Then, the high temperature A1 structure appears. By the following rapid quenching, the A1 structure remains as a metastable phase, even at room temperature. The other explanation is that the structural transformation is caused by a build-up of ballistic collisions and atomic displacements/replacements.

Figure 19 shows the Vickers hardness as a function of $\mathrm{Au}$ ion fluence. The surface hardness monotonically decreases with increasing ion fluence. This hardness decrease is absolutely due to the lattice structure transformation from $\mathrm{D}_{22}$ to the $\mathrm{A} 1$ structure. As seen in Figures 16 and 18, the $\mathrm{D}_{22}$ microstructure is more complicated than that of the A1 structure, and the Burgers vector for the tetragonal $\mathrm{D}_{22}$ structure is larger than that for fcc $\mathrm{A} 1$ structure. Therefore, dislocations can move more easily in the lattice of the $\mathrm{A} 1$ structure, and the $\mathrm{A} 1$ structure is more deformable than the $\mathrm{D}_{22}$ structure, causing the decrease in hardness. 


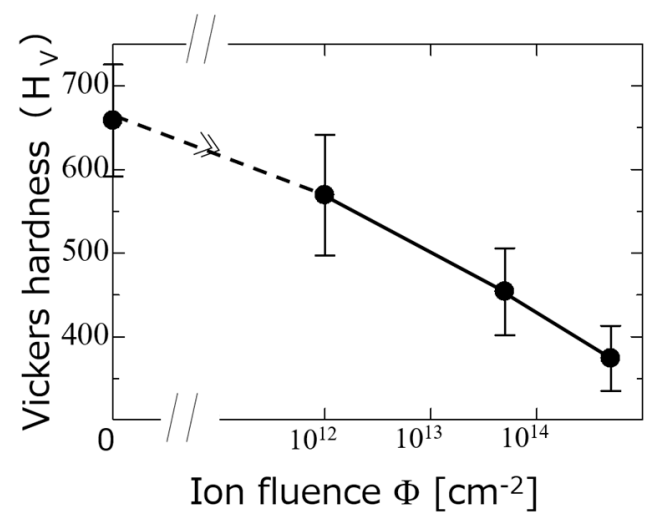

Figure 19. Vickers hardness for $\mathrm{Ni}_{3} \mathrm{~V}$ as a function of $16 \mathrm{MeV} \mathrm{Au}$ ion fluence.

A lattice structure transformation by the $\mathrm{Au}$ ion irradiation has also been found for the $\mathrm{Ni}_{3} \mathrm{Al}$ intermetallic compound. Figure 20 shows the phase diagram for Ni-Al binary alloy and the schematic diagram of the $\mathrm{L}_{2}$ lattice structure. The stoichiometric $\mathrm{Ni}_{3} \mathrm{Al}$ intermetallic compound has a cubic structure ( $\mathrm{L}_{2}$ structure) at room temperature. However, the $\mathrm{L} 1_{2}$ structure does not transform into a disordered fcc (A1) structure, but it is retained up to the melting temperature.
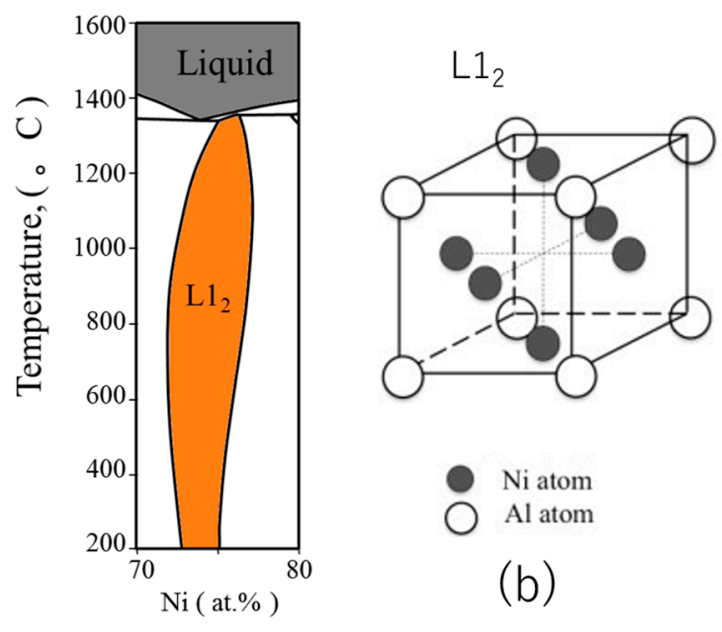

(b)

(a)

Figure 20. (a) Phase diagram for Ni-Al binary alloy and (b) schematic diagram of $\mathrm{L1}_{2}$ structure.

Figure 21 shows the GIXD spectra for the unirradiated $\mathrm{Ni}_{3} \mathrm{Al}$ specimen and those irradiated with $16 \mathrm{MeV} \mathrm{Au}$ ions to various fluences. For the unirradiated specimen, both fundamental peaks and the superlattice peaks can clearly be observed. By the Au ion irradiation to the fluence of $1 \times 10^{15} / \mathrm{cm}^{2}$, the superlattice peaks completely disappear, but the fcc (A1) fundamental peaks are still observed. The lattice structure transformation of $\mathrm{Ni}_{3} \mathrm{Al}$ from the $\mathrm{L}_{2}$ to $\mathrm{A} 1$ structure cannot be explained as an appearance of the high-temperature thermal equilibrium phase at room temperature, because the disordered fcc (A1) phase is not present in the thermal equilibrium phase diagram. Therefore, this structure transformation can be explained as originating from the build-up of ballistic collisions and atomic displacements/replacements. The lattice structure transformation of $\mathrm{Ni}_{3} \mathrm{Al}$ from the $\mathrm{L}_{2}$ to $\mathrm{A} 1$ structure accompanies the decrease in hardness, which is similar to the case of $\mathrm{Ni}_{3} \mathrm{~V}$. 


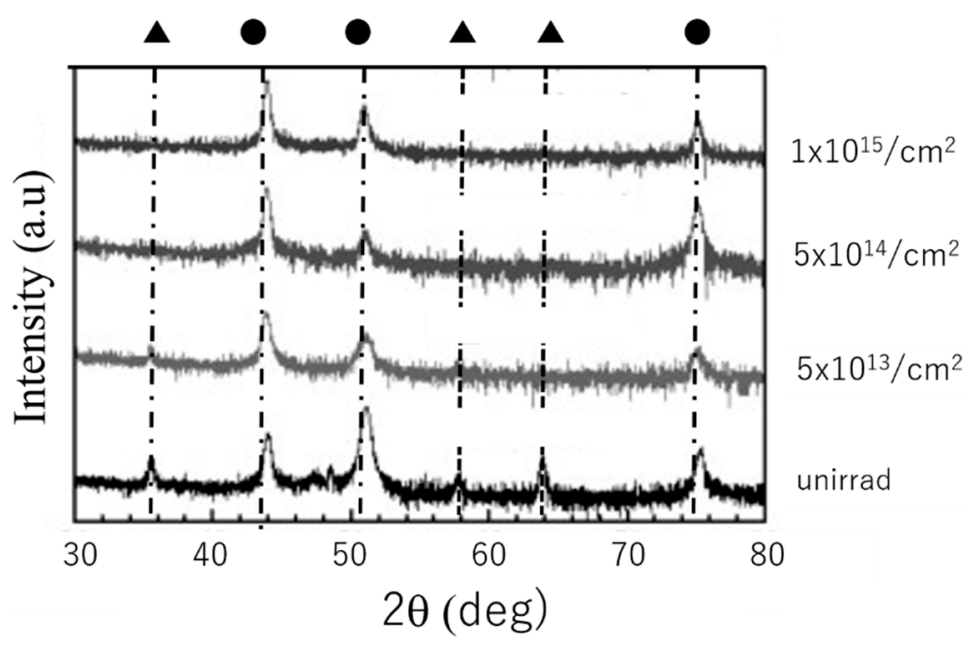

Figure 21. GIXD spectra for unirradiated $\mathrm{Ni}_{3} \mathrm{Al}$ and $16 \mathrm{MeV}$ Au ion-irradiated $\mathrm{Ni}_{3} \mathrm{Al}$. Ion fluences are shown at the right side of the figure. Solid triangles for $\mathrm{L}_{2}$ superlattice peaks and solid circles for A1 fundamental peaks.

Next, we will show the results for $\mathrm{Ni}_{3} \mathrm{Nb}$ and $\mathrm{Ni}_{3} \mathrm{Ta}$ intermetallic compounds. As their thermal equilibrium phase diagrams (Figure 22) indicate, the thermal equilibrium structure of $\mathrm{Ni}_{3} \mathrm{Nb}$ or $\mathrm{Ni}_{3} \mathrm{Ta}$ at room temperature is the orthorhombic $\left(\mathrm{D}_{\mathrm{a}}\right)$ or the monoclinic $\left(\mathrm{D}_{19}\right)$ structure, respectively.

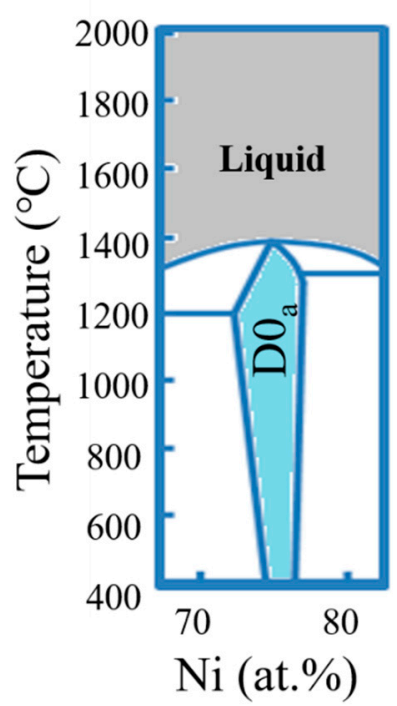

(a)

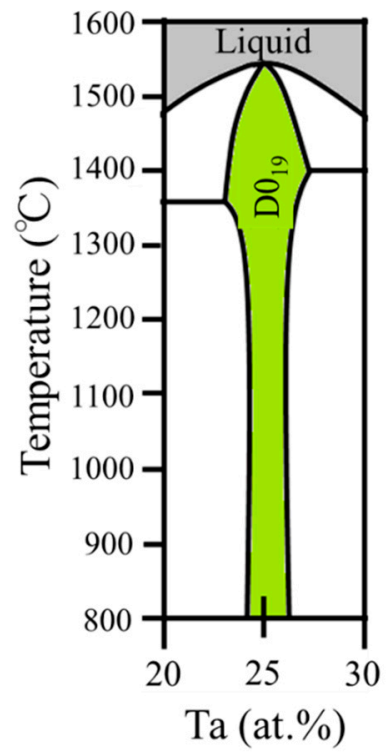

(b)

Figure 22. Phase diagrams of (a) Ni-Nb binary alloy and (b) Ni-Ta binary alloy.

These two structures are much more complicated than that of $\mathrm{Ni}_{3} \mathrm{~V}$ (tetragonal structure) or $\mathrm{Ni}_{3} \mathrm{Al}$ (cubic structure). They are retained up to the melting temperature, which is similar to the case of $\mathrm{Ni}_{3} \mathrm{Al}$.

Figure 23 shows the GIXD spectra for the unirradiated and $\mathrm{Au}$ ion-irradiated $\mathrm{Ni}_{3} \mathrm{Nb}$ specimens. All the peaks for the unirradiated specimen can be identified to those of the orthorhombic structure. By the Au ion irradiation, they are broadened and end up as only one broad peak around 43 degrees. Such a change in GIXD spectrum suggests that the lattice structure of $\mathrm{Ni}_{3} \mathrm{Nb}$ transforms from the orthorhombic structure to the amorphous phase by the Au ion irradiation. A similar irradiation effect has been found also for $\mathrm{Ni}_{3} \mathrm{Ta}$ intermetallic compound (Figure 24). 


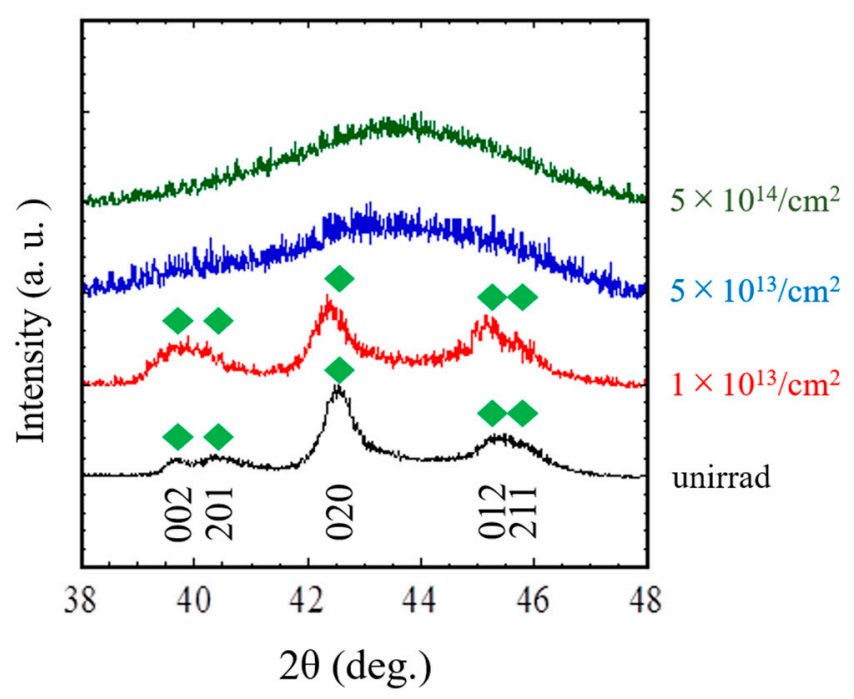

Figure 23. GIXD spectra for unirradiated and $16 \mathrm{MeV} \mathrm{Au}$ ion-irradiated $\mathrm{Ni}_{3} \mathrm{Nb}$. Indices and solid diamonds in the figure correspond to orthorhombic structure. Ion fluences are shown at the right side of the figure.

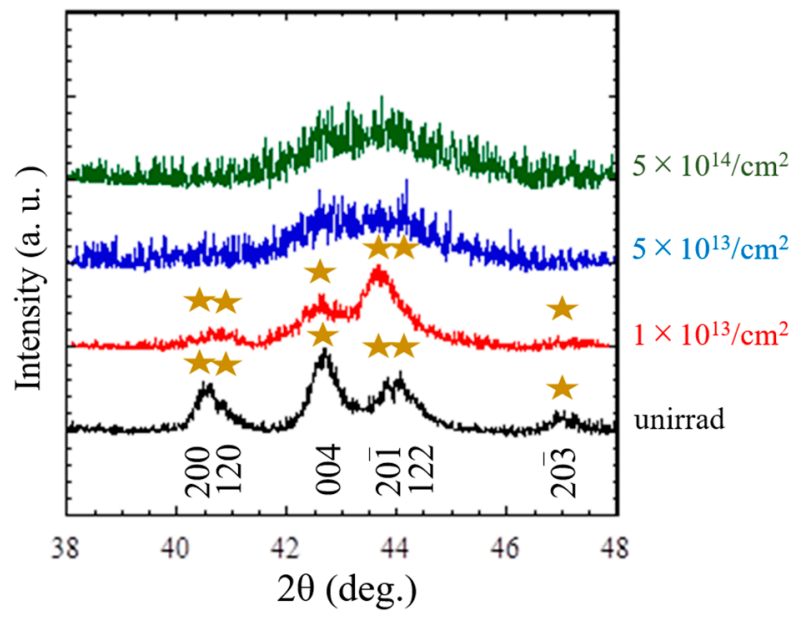

Figure 24. GIXD spectra for unirradiated and $16 \mathrm{MeV} \mathrm{Au}$ ion-irradiated $\mathrm{Ni}_{3} \mathrm{Ta}$. The indices and solid stars in the figure correspond to the monoclinic structure. Ion fluences are shown at the right side of the figure.

The amorphization of $\mathrm{Ni}_{3} \mathrm{Nb}$ and $\mathrm{Ni}_{3} \mathrm{Ta}$ was confirmed by the EXAFS measurements around $\mathrm{Nb}$-K absorption edge (X-ray energy of $18.9 \mathrm{keV}$ ) and Ta-L3 absorption edge (X-ray energy of $9.88 \mathrm{keV}$ ). As can be seen in Figure 25, even after the Au ion irradiation, the first peaks of the Fourier transformed EXAFS (FT-EXAFS) spectra, which correspond to nearest neighbor atoms for $\mathrm{Nb}$ or $\mathrm{Ta}$ atoms, are still more outstanding than any other peaks, the intensity of which is strongly reduced or almost vanishes by the Au ion irradiation. The change in FT-EXAFS spectra means that a long-range atomic ordering tends to disappear and only the short-range ordering still survives the ion irradiation. As the amorphous state corresponds to the liquid phase in the thermal equilibrium phase diagram, the amorphization of $\mathrm{Ni}_{3} \mathrm{Nb}$ and $\mathrm{Ni}_{3} \mathrm{Ta}$ can be explained as due to a rapid quenching of the molten state produced by the high-density energy deposition from the irradiating ions. The sequence of atomic displacements and replacements by ballistic collisions may be another possible mechanism for the amorphization of $\mathrm{Ni}_{3} \mathrm{Nb}$ and $\mathrm{Ni}_{3} \mathrm{Ta}$. 

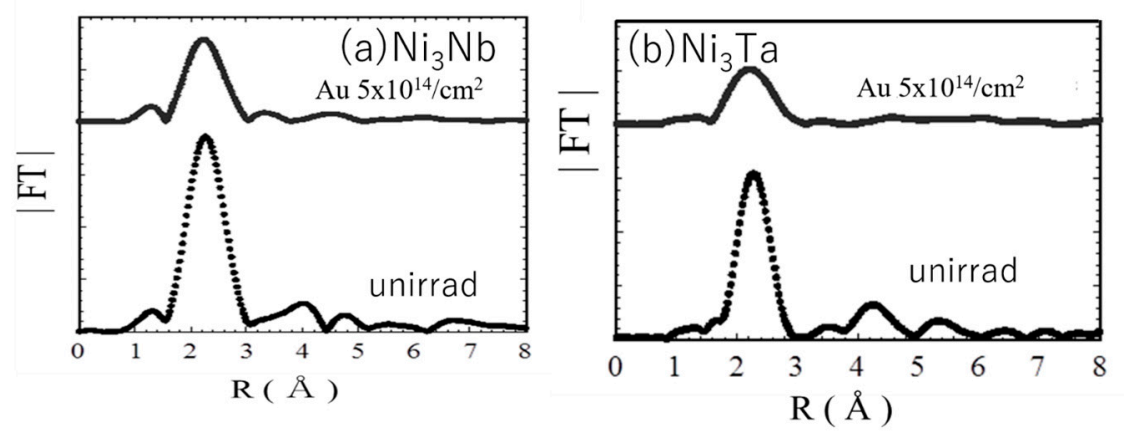

Figure 25. Fourier transformed extended X-ray Absorption Fine Structure (FT-EXAFS) spectra for unirradiated and $16 \mathrm{MeV}$ Au ion-irradiated (a) $\mathrm{Ni}_{3} \mathrm{Nb}$ and (b) $\mathrm{Ni}_{3} \mathrm{Ta}$.

Figure 26 shows that the increase in hardness of $\mathrm{Ni}_{3} \mathrm{Nb}$ and $\mathrm{Ni}_{3} \mathrm{Ta}$ is accompanied by their amorphization. This result is consistent with the conventional fact that the value of hardness for the amorphous state is larger than that for the crystal state [44,45]. Although the deformation mechanisms of amorphous materials have never been fully understood, a recent review article has discussed their details [46].

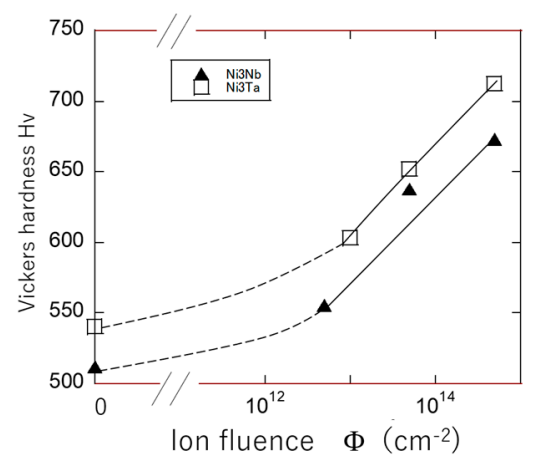

Figure 26. Vickers hardness as a function of $16 \mathrm{MeV} \mathrm{Au}$ ion fluence for $\mathrm{Ni}_{3} \mathrm{Nb}$ and $\mathrm{Ni}_{3} \mathrm{Ta}$.

3.2.2. Effect of Subsequent Thermal Treatments after the Irradiation on the Lattice Structures and Hardness of the Ni-Based Intermetallic Compounds

As mentioned before, the lattice structures and hardness of the Ni-based intermetallic compounds, which are modified by the ion irradiation, come out of the "irradiation-induced process", and they are far from the thermal equilibrium states. From now on, we will show how these non-thermal equilibrium or metastable states tend to recover to the original thermal equilibrium states by the subsequent thermal treatments after ion irradiation.

Figure 27 shows the effect of subsequent thermal treatment on the GIXD spectra of $\mathrm{Ni}_{3} \mathrm{~V}$. The $\mathrm{A} 1$ structure of the ion-irradiated $\mathrm{Ni}_{3} \mathrm{~V}$ recovers to the original $\mathrm{D}_{22}$ (tetragonal) structure by the thermal treatment at $773 \mathrm{~K}$ for $100 \mathrm{~min}$. The hardness of the ion-irradiated $\mathrm{Ni}_{3} \mathrm{~V}$ also tends to approach the original hardness value by the thermal treatment (see Figure 28). A similar trend in the recovery of the lattice structure and the hardness have also been observed in $\mathrm{Ni}_{3} \mathrm{Al}$ irradiated with $\mathrm{Au}$ ions. 


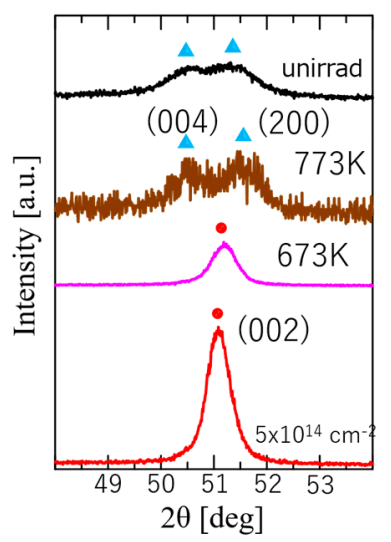

Figure 27. Change in grazing incidence $\mathrm{X}$-ray diffraction (GIXD) spectra of $\mathrm{Au}$ ion-irradiated $\mathrm{Ni}_{3} \mathrm{~V}$ by thermal treatment at $673 \mathrm{~K}$ and $773 \mathrm{~K}$.

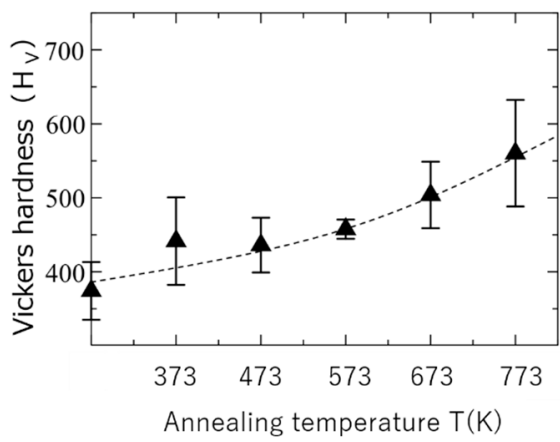

Figure 28. Thermal treatment temperature dependence of Vickers hardness for Au ion-irradiated $\mathrm{Ni}_{3} \mathrm{~V}$.

The changes in the GIXD spectra and the hardness of $\mathrm{Ni}_{3} \mathrm{Nb}$ by the thermal treatment are shown in Figure 29. The amorphous state of $\mathrm{Au}$ ion-irradiated $\mathrm{Ni}_{3} \mathrm{Nb}$ survives the thermal treatments up to $673 \mathrm{~K}$. It finally recovers to the thermal equilibrium orthorhombic structure by the thermal treatment at $773 \mathrm{~K}$. The hardness recovery is consistent with the recovery of the lattice structure. It fully recovers to the original hardness value at $773 \mathrm{~K}$.
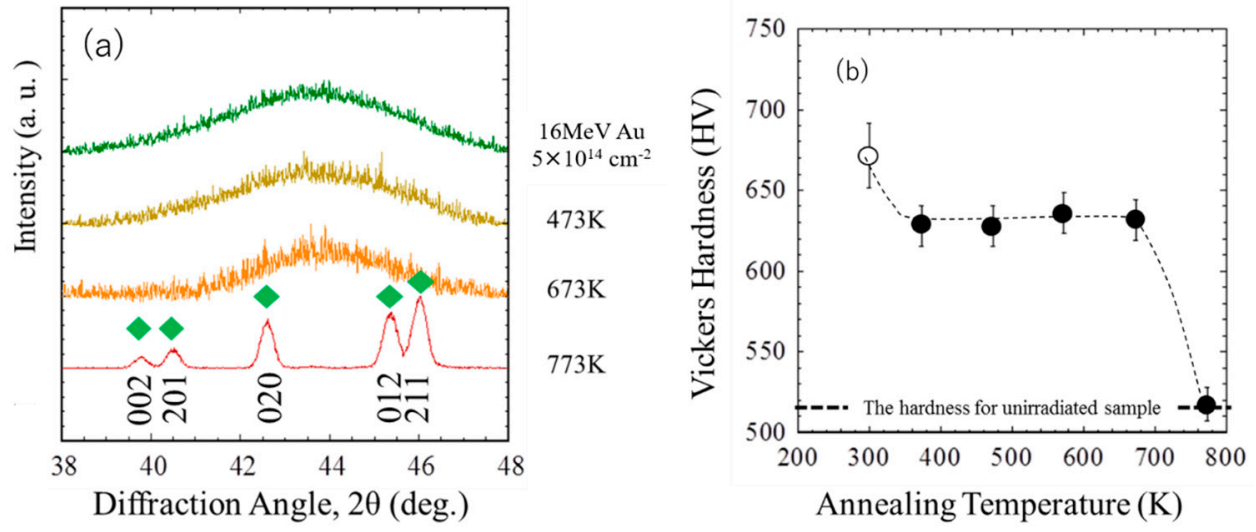

Figure 29. Effect of thermal treatment of $\mathrm{Ni}_{3} \mathrm{Nb}$ for (a) GIXD spectra and (b) Vickers hardness. Thermal treatment temperatures are shown at the right side of Figure 29a. The open circle in Figure 29b indicates the hardness value before thermal treatment. The hardness for unirradiated specimen is also shown in Figure 29b.

In the case of $\mathrm{Ni}_{3} \mathrm{Ta}$, Figure 30 shows that even by the thermal treatment at $973 \mathrm{~K}$, the lattice structure changes to orthorhombic and not the thermal equilibrium monoclinic structure. Although the 
hardness of the ion-irradiated $\mathrm{Ni}_{3} \mathrm{Ta}$ decreases with increasing the thermal treatment temperature, the resulting hardness after the thermal treatment at $973 \mathrm{~K}$ is still higher than the original hardness value. To realize the complete recovery, a thermal treatment at higher temperatures would be necessary.
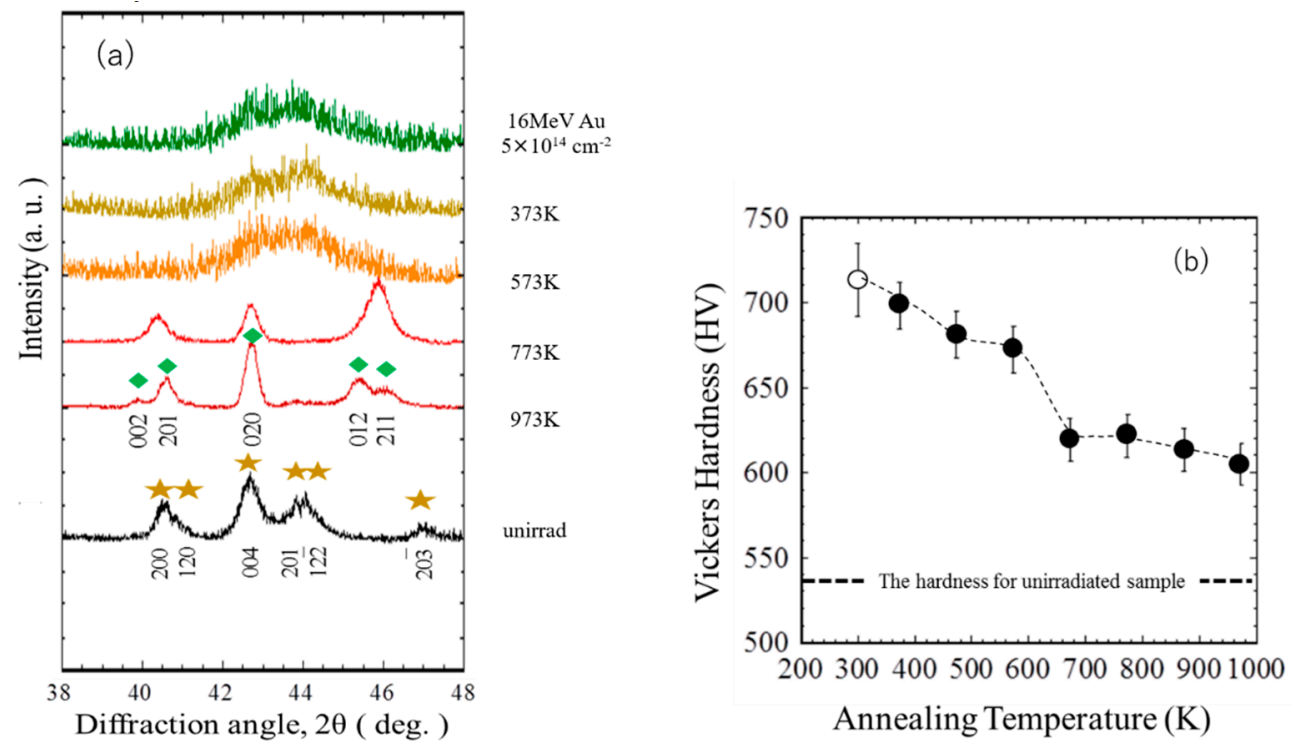

Figure 30. Effect of thermal treatment of $\mathrm{Ni}_{3} \mathrm{Ta}$ for (a) GIXD spectra and (b) Vickers hardness. Thermal treatment temperatures are shown at the right side of Figure 30a. The open circle in Figure 30b indicates the hardness value before thermal treatment. Hardness for the unirradiated specimen is also shown in Figure 30b.

The change in the lattice structure by the irradiation and the subsequent thermal treatment for Ni-based intermetallic compounds is schematically shown in Figure 31 in terms of the free energy. The abscissa of the figure means the coordinates of lattice atoms in the specimens, corresponding to the lattice structures. The lattice structure before the irradiation is considered to be the thermal equilibrium state, whereas the free energy of the irradiated specimens is higher than that of the thermal equilibrium structure. Moreover, the free energy for the amorphous state is higher than that for the disordered crystal state such as the A1 structure. The subsequent thermal treatment reduces the free energy of the specimen, and the lattice structure of the specimen tends to recover to the thermal equilibrium state.

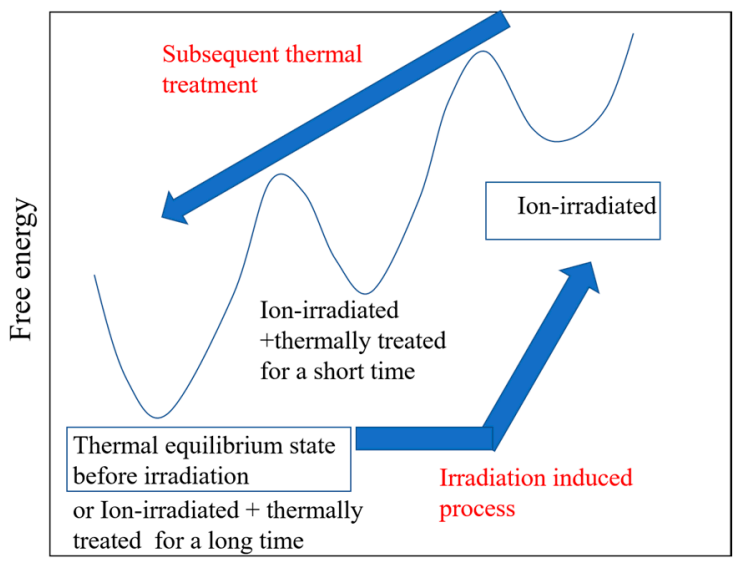

Coordinates of lattice atoms

Figure 31. Schematic diagram of change in free energy for "irradiation-induced process" and subsequent thermal annealing. 


\section{Industrial Application of Energetic Ion Irradiation to the Control of Surface Hardness of Metallic Alloys}

As compared with the conventional strengthening method, energetic ion irradiations can provide the increase in hardness of aluminum alloys at much lower temperatures and much more rapidly. Moreover, the penetration depth of the energetic ion used in our study is several $\mu \mathrm{m}$. Therefore, the irradiation with several $\mathrm{MeV}$ ions is an effective process method for the control of surface strengthening of aluminum alloys. In addition to energetic ion irradiations, the subsequent thermal aging is also very useful to obtain much higher surface hardness. Energetic ion irradiations could be applied as a surface strengthening method not only to Al dilute alloys but also to other supersaturated alloys such as solution-annealed and quenched CuTi binary alloys.

Although only four kinds of nickel-based intermetallic compounds have been investigated in the present study, some trend of the irradiation effect on the hardness can be revealed from our experimental results. For the intermetallic compounds with simple lattice structures, such as $\mathrm{Ni}_{3} \mathrm{Al}$ and $\mathrm{Ni}_{3} \mathrm{~V}$, the ion irradiation effect appears as the decrease in hardness. For those with more complicated structures, such as $\mathrm{Ni}_{3} \mathrm{Nb}$ and $\mathrm{Ni}_{3} \mathrm{Ta}$, the hardness is increased by the ion irradiation. In the former case, the combination of the energetic ion irradiation and the subsequent thermal treatment could be a useful process to overcome a low workability of intermetallic compounds as follows; firstly, the hardness of the specimen is reduced by the ion irradiation, and after a plastic working process, the thermal treatment is performed to recover to the original hardness. However, this process can be used only for the surface processing. In the latter case, the ion irradiation could be used for strengthening the specimen surface.

\section{Summary}

In the present report, we have reviewed our recent results on the modification of lattice structures and mechanical properties for the dilute aluminum alloys and the nickel-based intermetallic compounds by energetic ion irradiations. The energetic ion irradiation increases the surface hardness of the dilute aluminum alloys very rapidly, even at room temperature. The subsequent thermal aging at elevated temperature can provide a higher hardness.

The energetic ion irradiation also modified the lattice structures and the surface hardness of the nickel-based intermetallic compounds. The effect depends on the lattice structure before the irradiation. For the simple structures, the lattice structure changes to the disordered crystal structures, and the surface hardness is decreased by the ion irradiation. For more complicated structures, the ion irradiation results in the amorphization and increase in surface hardness. The subsequent thermal treatments also affect the structures and the hardness of these materials.

The energetic ion irradiation could be used as a process method for the surface hardness modifications of supersaturated alloys and intermetallic compounds.

Author Contributions: Writing-original draft preparation, A.I and F.H.; writing-review and editing, A.I. All authors have read and agreed to the published version of the manuscript.

Funding: This research received no external funding.

Acknowledgments: The present study has been carried out under a collaboration between Osaka Prefecture University and the National Institutes for Quantum and Radiological Science and Technology (QST), Japan Atomic Energy Agency (JAEA), National Institute for Materials Science (NIMS), Central Research Institute of Electrical Power Industry (CIEPI), The Wakasa Wan Energy Research Center (WERC) or Institute for Materials Research (IMR) of Tohoku University. The authors thank Y. Kaneno and S. Semboshi for their fruitful discussion.

Conflicts of Interest: The authors declare no conflict of interest. 


\section{References}

1. Lehmann, C. Interaction of Radiation with Solids and Elementary Defect Production; North-Holland Publishing Company: Amsterdam, The Netherlands, 1977.

2. Harish Kumar, H.G. High Energy Electron Irradiation Effects in Polymers; LAP LAMBERT Academic Publishing: Deutschland, Germany, 2011.

3. Ashworth, V.; Grant, W.A.; Procter, R.P.M. (Eds.) Ion Implantation into Metals; Pergamon Press: Oxford, UK, 1982.

4. Rimini, E. Ion Implantation: Basics to Device Fabrication; Springer: Berlin/Heidelberg, Germany, 1995.

5. Was, G.S. Fundamentals of Radiation Materials Science, Metals and Alloys; Springer: Berlin/Heidelberg, Germany, 2007.

6. Imaizumi, M.; Nakamura, T.; Takamoto, T.; Ohshima, T.; Tajima, M. Radiation degradation characteristics of component subcells in inverted metamorphic triple-junction solar cells irradiated with electrons and protons. Prog. Photovolt. Res. Appl. 2017, 25, 161-174. [CrossRef]

7. Mitsuda, T.; Kobayashi, I.; Kosugi, S.; Fujita, N.; Saitoh, Y.; Hori, F.; Semboshi, S.; Kaneno, Y.; Nishida, K.; Soneda, N.; et al. Hardening of Al-Cu-Mg alloy by energetic ion irradiation. J. Nucl. Mater. 2011, 408, 201-204. [CrossRef]

8. Mitsuda, T.; Kobayashi, I.; Kosugi, S.; Fujita, N.; Saitoh, Y.; Hori, F.; Semboshi, S.; Kaneno, Y.; Nishida, K.; Soneda, N.; et al. Hardness modification of aluminum-alloys by means of energetic ion irradiation and subsequent thermal aging. Nucl. Instrum. Methods B 2012, 272, 49-52. [CrossRef]

9. Ueyama, D.; Saitoh, Y.; Hori, F.; Kaneno, Y.; Nishida, K.; Dohi, K.; Soneda, N.; Semboshi, S.; Iwase, A. Effects of energetic heavy ion irradiation on hardness of Al-Mg-Si alloys. Nucl. Instrum. Methods B 2013, 314, 107-111. [CrossRef]

10. Hashimoto, A.; Kaneno, Y.; Matsui, T.; Saitoh, Y.; Iwase, A. Non-thermal equilibrium crystal structure and Vickers hardness of FeRh intermetallic compound irradiated with energetic heavy ions. Trans. Mater. Res. Soc. Jpn. 2013, 38, 329-331. [CrossRef]

11. Hashimoto, A.; Kaneno, Y.; Semboshi, S.; Yoshizaki, H.; Saitoh, Y.; Iwase, A. Effect of high temperature annealing on non-thermal equilibrium phases induced by energetic ion irradiation in $\mathrm{FeRh}$ and $\mathrm{Ni}_{3} \mathrm{~V}$ intermetallic compounds. Jpn. J. Appl. Phys. 2014, 53, 05FC08. [CrossRef]

12. Ueyama, D.; Semboshi, S.; Saitoh, Y.; Ishikawa, N.; Nishida, K.; Soneda, N.; Hori, F.; Iwase, A. Hardening induced by energetic electron beam for Cu-Ti alloys. Jpn. J. Appl. Phys. 2014, 53, 05FC04. [CrossRef]

13. Hashimoto, A.; Kaneno, Y.; Semboshi, S.; Yoshizaki, H.; Saitoh, Y.; Okamoto, Y.; Iwase, A. Microstructure evolution and hardness change in ordered $\mathrm{Ni}_{3} \mathrm{~V}$ intermetallic alloy by energetic ion irradiation. Nucl. Instrum. Methods B 2014, 338, 72-76. [CrossRef]

14. Ueyama, D.; Semboshi, S.; Saitoh, Y.; Hori, F.; Nishida, K.; Soneda, N.; Iwase, A. Modification of microstructure and hardness of $\mathrm{Cu}$-Ti alloy by means of energetic ion beam irradiation. Nucl. Instrum. Methods B 2014, 341, 53-57. [CrossRef]

15. Yoshizaki, H.; Hashimoto, A.; Kaneno, Y.; Semboshi, S.; Saitoh, Y.; Okamoto, Y.; Iwase, A. Modification of surface hardness for dual two-phase $\mathrm{Ni}_{3} \mathrm{Al}-\mathrm{Ni}_{3} \mathrm{~V}$ intermetallic compound by using energetic ion beam and subsequent thermal treatment. Nucl. Instrum. Methods B 2015, 345, 22-26. [CrossRef]

16. Yoshizaki, H.; Hashimoto, A.; Kaneno, Y.; Semboshi, S.; Hori, F.; Saitoh, Y.; Iwase, A. Energetic ion beam induced crystal phase transformation and resulting hardness change in $\mathrm{Ni}_{3} \mathrm{Al}$ intermetallic compound. Nucl. Instrum Methods B 2015, 354, 287-291. [CrossRef]

17. Ueyama, D.; Saitoh, Y.; Ishikawa, N.; Ohmura, T.; Semboshi, S.; Hori, F.; Iwase, A. Hardness modification of Al-Mg-Si alloy by using energetic ion beam irradiation. Nucl. Instrum. Methods B 2015, 351, 1-5. [CrossRef]

18. Kojima, H.; Yoshizaki, H.; Kaneno, Y.; Semboshi, S.; Hori, F.; Saitoh, Y.; Okamoto, Y.; Iwase, A. Lattice structure transformation and change in surface hardness of $\mathrm{Ni}_{3} \mathrm{Nb}$ and $\mathrm{Ni}_{3}$ Ta intermetallic compounds induced by energetic ion beam irradiation. Nucl. Istrum. Methods B 2016, 372, 72-77. [CrossRef]

19. Mayumi, R.; Semboshi, S.; Okamoto, Y.; Saitoh, Y.; Yoshiie, T.; Iwase, A. Radiation enhanced precipitation of solute atoms in $\mathrm{AlCu}$ binary alloys-Energetic ion irradiation experiment and computer simulation. Trans. Mater. Res. Soc. Jpn. 2017, 42, 9-14. [CrossRef] 
20. Kojima, H.; Kaneno, Y.; Ochi, M.; Semboshi, S.; Hori, F.; Saitoh, Y.; Ishikawa, N.; Okamoto, Y.; Iwase, A. Ion species/energy dependence of irradiation-induced lattice structure transformation and surface hardness of $\mathrm{Ni}_{3} \mathrm{Nb}$ and $\mathrm{Ni}_{3} \mathrm{Ta}$ intermetallic compounds. Mater. Trans. 2017, 58, 739-748. [CrossRef]

21. Kojima, H.; Ochi, M.; Kaneno, Y.; Semboshi, S.; Hori, F.; Saitoh, Y.; Iwase, A. Thermal stability of energetic ion irradiation induced amorphization for $\mathrm{Ni}_{3} \mathrm{Nb}$ and $\mathrm{Ni}_{3} \mathrm{Ta}$ intermetallic compounds. Trans. Mat. Res. Soc. Jpn. 2017, 42, 41-45. [CrossRef]

22. Ochi, M.; Kojima, H.; Fukuda, K.; Kaneno, Y.; Semboshi, S.; Hori, F.; Saitoh, Y.; Iwase, A. Thermal stability of irradiation-induced metastable lattice structures in NiTi intermetallic compound. Trans. Mater. Res. Soc. Jpn. 2018, 43, 53-56. [CrossRef]

23. Ochi, M.; Kojima, H.; Hori, F.; Kaneno, Y.; Semboshi, S.; Saitoh, Y.; Okamoto, Y.; Ishikawa, N.; Iwase, A. Effect of elastic collisions and electronic excitation on lattice structure of NiTi bulk intermetallic compound irradiated with energetic ions. Nucl. Instrum. Methods B 2018, 427, 14-19. [CrossRef]

24. Fukuzumi, M.; Chimi, Y.; Ishikawa, N.; Ono, F.; Komatsu, S.; Iwase, A. Swift heavy ion induced magnetic phase transition of FeRh alloy. Nucl. Instrum. Methods B 2005, 230, 269-273. [CrossRef]

25. Iwase, A.; Fukuzumi, M.; Zushi, Y.; Suzuki, M.; Takagaki, M.; Kawamura, N.; Chimi, Y.; Ishikawa, N.; Mizuki, J.; Ono, F. Study on irradiation-induced magnetic transition in FeRh alloys by means of Fe K-edge XMCD spectroscopy. Nucl. Instrum. Methods B 2007, 256, 429-433. [CrossRef]

26. Zushi, Y.; Fukuzumi, M.; Chimi, Y.; Ishikawa, N.; Ono, F.; Iwase, A. Ion-species dependence of swift heavy ion induced ferromagnetism of Fe-50 at.\% Rh alloy at low temperatures. Nucl. Instrum. Methods B 2007, 256, 434-437. [CrossRef]

27. Kosugi, S.; Fujita, N.; Zushi, Y.; Matsui, T.; Ishikawa, N.; Saitoh, Y.; Iwase, A. Modification of magnetic properties of FeRh intermetallic compounds by energetic ion beam bombardment. Nucl. Instrum. Methods. B 2009, 267, 1612-1615. [CrossRef]

28. Nao, F.; Matsui, T.; Kosugi, S.; Satoh, T.; Saitoh, Y.; Takano, K.; Koka, M.; Kamiya, T.; Seki, S.; Iwase, A. Micronmeter-sized magnetic patterning of FeRh films using an energetic ion microbeam. Jpn. J. Appl. Phys. 2010, 49, 060211.

29. Kosugi, S.; Matsui, T.; Ishikawa, N.; Itou, M.; Sakurai, Y.; Aikoh, K.; Shimizu, K.; Tahara, Y.; Hori, F.; Iwase, A. Study on ion-irradiation-induced ferromagnetism in FeRh intermetallic compound by means of magnetic Compton scattering. J. Appl. Phys. 2011, 109, 07B737. [CrossRef]

30. Aikoh, K.; Tohki, A.; Matsui, T.; Iwase, A.; Satoh, T.; Takano, K.; Kohka, M.; Saitoh, Y.; Kamiya, T.; Ohkochi, T.; et al. MFM and PEEM observation of micrometer-sized magnetic dot arrays fabricated by ion-microbeam irradiation in FeRh thin films. J. Synchrotron Rad. 2012, 19, 223-226. [CrossRef] [PubMed]

31. Shimizu, K.; Kosugi, S.; Tahara, Y.; Yasunaga, K.; Kaneta, Y.; Ishikawa, N.; Hori, F.; Matsui, T.; Iwase, A. Change in magnetic properties induced by swift heavy ion irradiation in $\mathrm{CeO}_{2}$. Nucl. Instrum. Mathods B 2012, 286, 291-294. [CrossRef]

32. Tohki, A.; Aikoh, K.; Shinoda, R.; Ohkochi, T.; Kotsugi, M.; Nakamura, T.; Kinoshita, T.; Iwase, A.; Matsui, T. $\mathrm{X}$-ray magnetic circular dichroism photoemission electron microscopy of focused ion beam-induced magnetic patterns on iron-rhodium surfaces. Nucl. Instrum. Methods B 2013, 302, 51-54. [CrossRef]

33. Koide, T.; Saitoh, Y.; Sakamaki, M.; Amemiya, K.; Iwase, A.; Matsui, T. Change in magnetic and structural properties of FeRh thin films by gold cluster ion beam irradiation with the energy of 1.67MeV/atom. J. Appl. Phys. 2014, 115, 17B722. [CrossRef]

34. Kishino, T.; Shinoda, R.; Shimizu, K.; Saitoh, Y.; Ishikawa, N.; Okamoto, Y.; Hori, F.; Matsui, T.; Iwase, A. Effect of $10 \mathrm{MeV}$ iodine ion irradiation on the magnetic properties and lattice structure of $\mathrm{CeO}_{2}$. Jpn. J. Appl. Phys. 2014, 53, 05FC07. [CrossRef]

35. Koide, T.; Satoh, T.; Kohka, M.; Saitoh, Y.; Kamiya, T.; Ohkouchi, T.; Kotsugi, M.; Kinoshita, T.; Nakamura, T.; Iwase, A.; et al. Magnetic patterning of FeRh thin films by energetic light ion microbeam irradiation. Jpn. J. Appl. Phys. 2014, 53, 05FC06. [CrossRef]

36. Soma, R.; Saitoh, Y.; Sakamaki, M.; Amemiya, K.; Iwase, A.; Matsui, T. Irradiation effect on magnetic properties of FeRh thin films with energetic C60 cluster ion beam. AIP Adv. 2018, 8, 056433. [CrossRef]

37. Soma, R.; Iwase, A.; Saitoh, Y.; Matsui, T. Directional magnetic modification of iron rhodium compound by ion irradiation and annealing. Mater. Trans. 2019, 60, 476-478. [CrossRef] 
38. Fukuda, K. Clustering of metal atoms by high energy ion implantation in oxides and the effects on magnetic and optical properties. In Proceedings of the 27th International Conference on Atomic Collisions in Solids (ICACS 27), Lanzhou, China, 24-29 July 2016.

39. Ziegler, J. SRIM-The Stopping and Range of Ions in Matter. Available online: http://www/srim.org/ (accessed on 5 January 2020).

40. Iwase, A.; Sasaki, S.; Iwata, T.; Nihira, T. Anomalous reduction of stage-I recovery in nickel irradiated with heavy ions in the energy range 100-120 MeV. Phys. Rev. Lett. 1987, 58, 2450-2453. [CrossRef] [PubMed]

41. Dunlop, A.; Lesueur, D.; Legrand, P.; Dammak, H.; Dural, J. Effects induced by high electronic excitations in pure metals: A detailed study in iron. Nucl. Instrum. Methods B 1994, 90, 330-338. [CrossRef]

42. Tobita, T.; Nakagawa, S.; Takeuchi, T.; Suzuki, M.; Ishikawa, N.; Chimi, Y.; Saitoh, Y.; Soneda, N.; Nishida, K.; Ishino, S.; et al. Effects of irradiation induced $\mathrm{Cu}$ clustering on Vickers hardness and electrical resistivity of Fe-Cu model alloys. J. Nucl. Mater. 2014, 452, 241-247. [CrossRef]

43. Russel, K.C.; Brown, L.M. A dispersion strengthening model based on differing elastic moduli applied to the iron-copper system. Acta Metall. 1972, 20,969-974. [CrossRef]

44. Shibata, T.; Kawanishi, M.; Nagahora, J.; Inoue, A.; Masumoto, T. High specific strength of extruded Mg-Al-Ge alloys produced by rapid solidification processing. Mater. Sci. Eng. 1994, A179/A180, 632-636. [CrossRef]

45. Zhang, T.; Inoue, A. Mechanical properties of Zr-Ti-Al-Ni-Cu bulk amorphous sheets prepared by squeeze casting. Mater. Trans. 1998, 39, 1230-1237. [CrossRef]

46. Nicolas, A.; Ferrero, E.E.; Martens, K.; Barrat, J.-L. Deformation and flow of amorphous solids: An updated review of mesoscale elastoplastic models. arXiv 2018, arXiv:1708.09194v4.

(C) 2020 by the authors. Licensee MDPI, Basel, Switzerland. This article is an open access article distributed under the terms and conditions of the Creative Commons Attribution (CC BY) license (http://creativecommons.org/licenses/by/4.0/). 